\title{
Alcohol Drinking Alters Stress Response to Predator Odor via Extended Amygdala Kappa Opioid Receptor Signaling in Male Mice
}

Authors: Lara S. Hwa, Sofia Neira, Meghan E. Flanigan, Christina M. Stanhope, Melanie M.

Pina, Dipanwita Pati, Olivia J. Hon, Waylin Yu, Emily Kokush, Rachel Calloway, Kristen Boyt,

Thomas L. Kash*

Affiliations: Bowles Center for Alcohol Studies, Department of Pharmacology, University of

North Carolina at Chapel Hill, 104 Manning Drive, Chapel Hill, NC, 27599, USA

*Correspondence

Thomas L. Kash, Ph.D.

John R. Andrews Distinguished Professor

Bowles Center for Alcohol Studies

Department of Pharmacology

University of North Carolina School of Medicine

Chapel Hill, NC 27599, USA

tkash@email.unc.edu

(919)843-7867 


\begin{abstract}
Maladaptive responses to stress are a hallmark of alcohol use disorder, but the mechanisms that underlie this are not well characterized. Here we show that kappa opioid receptor signaling in the bed nucleus of the stria terminalis (BNST) is a critical molecular substrate underlying abnormal stress responses to predator odor following heavy alcohol drinking. Exposure to predator odor during protracted withdrawal from intermittent alcohol drinking resulted in enhanced prefrontal cortex (PFC)-driven excitation of prodynorphin-containing neurons in the BNST compared to drinking or stress alone. Furthermore, deletion of prodynorphin in the BNST and chemogenetic inhibition of the PFC-BNST pathway restored abnormal responses to predator odor in alcoholexposed mice. These findings suggest that increased corticolimbic drive may promote abnormal stress behavioral responses to predator odor during protracted withdrawal from heavy drinking. Various nodes of this PFC-BNST dynorphin-related circuit may serve as potential targets for potential therapeutic mediation as well as biomarkers of negative responses to stress following heavy alcohol drinking.
\end{abstract}

Impact Statement: Heavy alcohol drinking primes dynorphin / kappa opioid systems in the bed nucleus of the stria terminalis to alter stress responses in mice.

Competing Interests: Authors declare no competing interests.

Data and materials availability: All data are available in the main text or the supplementary materials. 


\section{Introduction}

Alcohol abuse exacts a tremendous toll on society, and long term drinking can dysregulate stress systems in the brain. Prolonged alcohol drinking and withdrawal experiences result in enhanced responsiveness and behavioral sensitivity to stress during protracted

abstinence (Heilig et al. 2010). Reciprocally, clinical studies show that negative stress coping is predictive of higher levels of drinking in alcoholics (Noone et al. 1999). As blunted responses to stress have been identified in alcohol-dependent people (Sinha et al. 2011), it is essential to consider mechanisms by which alcohol drinking impacts stress responses during protracted abstinence. While many studies have utilized animal models to investigate how stress drives increased alcohol drinking behaviors (Becker et al. 2011, Gilpin and Weiner 2017), few have explored the effects of alcohol drinking on subsequent stress responsivity.

Chronic alcohol exposure engages brain stress signaling systems that influence drinking behaviors in a dynamic and complex manner (Koob and Kreek 2007). One such stress system is the neuropeptide prodynorphin (Pdyn) and its receptor, the kappa opioid receptor (KOR), which has been studied in the contexts of both mood and alcohol use disorders (Lutz and Kieffer 2013). Limbic structures implicated in alcohol and stress behaviors, such as the bed nucleus of the stria terminalis (BNST), are rich in Pdyn and KOR (Le Merrer et al. 2009). The BNST is an integrative hub that may mediate the negative affective state associated with chronic alcohol use and withdrawal (Koob 2009, Kash 2012). KORs throughout the extended amygdala and the

BNST alter anxiety-like behavior in mice (Bruchas et al. 2009; Crowley et al. 2016) and mediate stress-induced reinstatement for alcohol reinforcement (Lê et al. 2018).

In this study, we tested whether BNST KOR/Pdyn signaling regulates abnormal stress responses after long-term alcohol drinking. We employed the ethologically relevant predator 
odor trimethylthiazoline (TMT) as a stressor, which is a compound isolated from fox feces. In rats and $\mathrm{C} 57 \mathrm{BL} / 6 \mathrm{~J}$ mice, TMT activates specific brain regions involved in stress, anxiety, and fear, including the BNST (Day et al. 2004, Asok et al. 2013, Janitzky et al. 2015), and inactivation of the BNST blocks TMT-induced freezing (Fendt et al. 2003). Recent work suggests that distinct neuropeptide circuits in the BNST may drive opposing emotional states (Giardino et al. 2018), which may be dependent on inputs from cortical sites to affect stress coping behaviors (Johnson et al. 2019). The current series of experiments investigate whether Pdyn neurons and KOR signaling in the BNST can modulate behavioral responses to stress in alcohol-exposed animals. We show that dysregulation of cortical inputs to BNST Pdyn neurons and BNST Pdyn neurons themselves underlie lasting behavioral changes to stressors that emerge after chronic drinking. This is a criticalarea of study, as mitigating stress responses can contribute to improved alcohol relapse outcomes.

\section{Results} Male C57BL/6J mice were given six weeks of intermittent access to alcohol (EtOH), a protocol known to induce heavy voluntary drinking (Hwa et al. 2011), before behavioral testing during protracted (7-10 days) abstinence [Fig 1A]. Mice consumed high amounts of EtOH [Fig 1B] and increased their EtOH preference over time [Fig 1C]. Further, mice achieved greater than $80 \mathrm{mg} / \mathrm{dl}$ blood EtOH concentrations, indicative of intoxication, which correlated with drinking behavior [Fig 1D; $\left.\mathrm{R}^{2}=0.59, \mathrm{p}=0.0036\right]$. To test stress responsivity during protracted abstinence from EtOH, mice were exposed to the predator odor TMT in the home cage (Hwa et al. 2019). Both water $\left(\mathrm{H}_{2} \mathrm{O}\right)$-drinking controls and $\mathrm{EtOH}$ drinking mice showed a TMT-induced increase in plasma corticosterone [Fig 1E; TMT main effect: $\mathrm{F}_{1,10}=26.79$, p=0.0004, $\mathrm{H}_{2} \mathrm{O}$ BL vs TMT 
$\mathrm{t}_{10}=3.32, \mathrm{p}=0.0154$, EtOH BL vs TMT $\left.\mathrm{t}_{10}=3.99, \mathrm{p}=0.005\right]$. We tracked the location of the mouse relative to the TMT and measured the time spent contacting the TMT and in the far corners [Fig 1F]. EtOH-drinking mice displayed reduced avoidance of the TMT compared to the water $\left(\mathrm{H}_{2} \mathrm{O}\right)$-drinking controls during protracted abstinence [Fig 1G-H]. As an initial screen to identify altered behavior separate from avoidance, we examined stress-related and exploratory behavior in three mice per condition on a second-by-second basis [Fig 1 Suppl 1]. Since the primary difference among stress-related activities was burying, we focused our further analyses on this typical behavior in response to noxious stimuli (Hwa et al. 2019). Specifically, EtOH drinkers demonstrated reduced burying behavior compared to controls [Fig $1 \mathrm{H}]$.

At this protracted time point, another group of $\mathrm{C} 57 \mathrm{BL} / 6 \mathrm{~J}$ male mice was tested in the elevated plus maze [Fig 1 Suppl 2A]. EtOH mice showed reduced time spent in the open arms of the elevated plus maze [Fig 1 Suppl $\left.2 \mathrm{~B} ; \mathrm{t}_{18}=2.81, \mathrm{p}=0.0115\right]$ and equal time in the closed arms as controls [Fig 1 Suppl 2C]. It is possible that the difference in response to TMT was driven by a change in olfaction. To determine whether olfaction was intact in the EtOH mice, peanut oil was tested as an alternative, appetitive odor. $\mathrm{EtOH}$ and $\mathrm{H}_{2} \mathrm{O}$ mice spent similar amounts of time contacting the peanut oil [Fig 1 Suppl 2D-E] and in the far corners [Fig 1 Suppl 2F].

Previous studies have shown that activation of the Pdyn/KOR system can modulate stress-induced EtOH seeking (Lê et al. 2018), so we tested if KOR blockade could alter drinkinginduced stress behavior. Systemic treatment with $5 \mathrm{mg} / \mathrm{kg}$ of the long-acting KOR antagonist norBNI 16 hours prior to TMT exposure reduced EtOH-induced increases in TMT contact compared to saline-injected EtOH mice [Fig 1G; Drug main effect $\mathrm{F}_{1,35}=5.45$, p=0.0254, EtOH main effect $\mathrm{F}_{1,35}=15.80$, $\mathrm{p}=0.0003$; saline $\mathrm{H}_{2} \mathrm{O}$ vs $\mathrm{EtOH} \mathrm{t}_{35}=2.95$, $\mathrm{p}=0.0113$; EtOH saline vs norBNI t35=4.12, $\mathrm{p}=0.0004]$. NorBNI also alleviated reductions in burying behavior in $\mathrm{EtOH}$ 
mice compared to saline-injected EtOH drinkers [Fig 1I; interaction $\mathrm{F}_{1,35}=9.70$, $\mathrm{p}=0.0037$; saline $\mathrm{H}_{2} \mathrm{O}$ vs saline $\mathrm{EtOH} \mathrm{t}_{35}=4.52, \mathrm{p}=0.0001 ; \mathrm{EtOH}$ saline vs norBNI $\left.\mathrm{t}_{35}=2.47, \mathrm{p}=0.0367\right]$. Sample ethograms depict changes in burying behavior in the EtOH norBNI group compared to EtOH saline controls and identify other behaviors mice were engaged in during this test such as rearing, walking, and freezing [Fig 1 Suppl 1]. Given the potential therapeutic relevance of targeting the protracted time point, we next focused on identifying the mechanism for this long-lasting adaptation in the brain's dynorphin system.

The BNST is a brain site known for its involvement in stress, anxiety, and addiction, and is regulated by the Pdyn/KOR system (Crowley et al. 2016). Previous studies in rats have shown that TMT increases BNST activity using c-Fos as a marker for active neuronal populations (Day et al. 2004, Asok et al. 2013), so we examined this in a line of Pdyn-IRES-Cre x Rosa26-floxstop-L10-GFP (Pdyn-GFP) mice (Al-Hasani et al. 2015) after intermittent EtOH or $\mathrm{H}_{2} \mathrm{O}$ consumption [Fig 2A]. TMT elicited robust dorsal BNST c-Fos immunostaining, which was greater in $\mathrm{EtOH}$ mice compared to $\mathrm{H}_{2} \mathrm{O}$ mice [Fig 2B-C; interaction $\mathrm{F}_{1,23}=12.45$, $\mathrm{p}=0.0018 ; \mathrm{H}_{2} \mathrm{O}$ non-stress (NS) vs TMT t $23=6.51, \mathrm{p}<0.0001 ;$ EtOH NS vs TMT $\mathrm{t}_{23}=10.13, \mathrm{p}<0.0001 ; \mathrm{TMT} \mathrm{H}_{2} \mathrm{O}$ vs TMT EtOH t23=3.92, p=0.0041]. Furthermore, TMT increased expression of Pdyn GFPexpressing neurons in the BNST versus non-stressed (NS) mice [Fig 2D; TMT main effect $\left.\mathrm{F}_{1,23}=4.56, \mathrm{p}=0.0437\right]$. Importantly, colocalization of $\mathrm{c}-\mathrm{Fos}$ in Pdyn-containing cells $\left(\mathrm{BNST}^{\mathrm{PDYN}}\right.$ ) was largest in the stressed EtOH group [Fig 2E; interaction $\mathrm{F}_{1,23}=5.91$, $\mathrm{p}=0.0233$; EtOH NS vs TMT $\mathrm{t}_{23}=4.66, \mathrm{p}=0.0007 ; \mathrm{TMT}_{2} \mathrm{O}$ vs TMT EtOH t23 $\left.=3.65, \mathrm{p}=0.0081\right]$, suggesting an interaction between EtOH, Pdyn, and predator odor stress in the BNST. To determine whether EtOH history affected Pdyn/KOR expression in the BNST, a group of C57BL/6J mice underwent EtOH or $\mathrm{H}_{2} \mathrm{O}$ drinking and were exposed to TMT predator odor before the BNST was taken for 
fluorescent in situ hybridization with Pdyn and Oprk1 probes [Fig 2F]. Pdyn expression was heightened in the EtOH group compared to $\mathrm{H}_{2} \mathrm{O}$ group [Fig G-H, Pdyn intensity: $\mathrm{t}_{10}=2.99$, p=0.0136; Fig 2I, Pdyn counts: $t_{10}=2.21, p=0.0512$ ], but Oprk1 expression was not altered [Fig $2 \mathrm{~J}]$. (Fendt et al. 2003); however, the role of KOR signaling in this process has not been explored. Thus, we next tested whether microinfusions of norBNI directly into the BNST would alter behavioral responses to TMT during protracted abstinence [Fig 3A-C, Fig 3 Suppl 1]. Importantly, norBNI or PBS infusion into the BNST did not affect distance traveled during the TMT test [Fig 3D]. However, similar to systemic administration, intra-BNST norBNI reduced contact with TMT in the EtOH mice [Fig 3E; interaction $\mathrm{F}_{1,35}=4.30$, p=0.0454; $\mathrm{PBS} \mathrm{H}_{2} \mathrm{O}$ vs $\mathrm{EtOH}_{35}=3.29, \mathrm{p}=0.0105, \mathrm{EtOH}$ PBS vs norBNI $\left.\mathrm{t}_{35}=3.32, \mathrm{p}=0.0105\right]$ with no effect on time spent in the far corners of the home cage [Fig 3F]. EtOH mice showed significantly less burying behavior in response to TMT compared to $\mathrm{H}_{2} \mathrm{O}$ mice, but there was no effect of drug in EtOH mice [Fig 3G; EtOH main effect $\mathrm{F}_{1,35}=42.65$, $\mathrm{p}<0.001$; $\mathrm{PBS} \mathrm{H}_{2} \mathrm{O}$ vs EtOH t35=4.06, $\mathrm{p}=0.0010$; norBNI $\mathrm{H}_{2} \mathrm{O}$ vs $\mathrm{EtOH}_{35}=5.19$, $\left.\mathrm{p}<0.001\right]$. Intra-BNST norBNI did not alter behavior in the elevated plus maze [Fig 3H-I].

We next examined the synaptic activity of BNST ${ }^{\mathrm{PDYN}}$ neurons following TMT exposure by recording spontaneous excitatory and inhibitory post-synaptic currents (sEPSC, sIPSC) in Pdyn-GFP mice during 7-10 days protracted abstinence [Fig 4A]. TMT increased sEPSC frequency $(\mathrm{Hz})$ in EtOH and $\mathrm{H}_{2} \mathrm{O}$ drinkers compared to non-stressed (NS) mice [Fig 4B; TMT main effect $\mathrm{F}_{1,50}=18.24, \mathrm{p}<0.0001 ; \mathrm{H}_{2} \mathrm{O}$ NS vs TMT t50=3.38, $\mathrm{p}=0.0028$; EtOH NS vs TMT $\left.\mathrm{t}_{50}=2.75, \mathrm{p}=0.0167\right]$ with no alterations in sIPSC frequency [Fig. 4C]. EtOH and TMT did not 
impact sEPSC and sIPSC amplitude [Fig 4 Suppl 1A-B]. Increased sEPSC/sIPSC ratios also reflected heightened excitatory drive onto $\mathrm{BNST}^{\mathrm{PDYN}}$ cells in stressed mice regardless of drinking history [Fig 4D; TMT main effect $\mathrm{F}_{1,50}=23.61$, $\mathrm{p}<0.0001 ; \mathrm{H}_{2} \mathrm{O}$ NS vs TMT $\mathrm{t}_{50}=2.50$, $\mathrm{p}=0.0312 ;$ EtOH NS vs TMT $\mathrm{t}_{50}=4.24, \mathrm{p}=0.0002 ; \mathrm{TMT}_{2} \mathrm{O}$ vs EtOH $\left.\mathrm{t}_{50}=2.25, \mathrm{p}=0.0566\right]$. In the

EtOH drinking, stressed group, there was a moderate correlation between cumulative EtOH drinking $(\mathrm{g} / \mathrm{kg})$ and sEPSC frequency [Fig 4 Suppl $1 \mathrm{C} ; \mathrm{R}^{2}=0.38, \mathrm{p}=0.1062$ ] and sEPSC/sIPSC ratio [Fig 4 Suppl 1D; $\left.\mathrm{R}^{2}=0.31, \mathrm{p}=0.1545\right]$. We next examined if KOR played a role in driving this cellular phenotype. Systemic norBNI pretreatment reduced sEPSC frequency in BNST ${ }^{\mathrm{PDYN}}$ cells [Fig 4E-F; norBNI main effect $\mathrm{E}_{1,34}=7.94$, $\mathrm{p}=0.008$, EtOH TMT saline vs norBNI $\mathrm{t}_{34}=3.22$, $\mathrm{p}=0.0056]$, but not sIPSC frequency [Fig 4G], with an increase in the sEPSC/sIPSC ratio being suppressed by norBNI in the EtOH TMT mice [Fig 4H; norBNI main effect $\mathrm{F}_{1,34}=9.36$, $\mathrm{p}=0.0043$; EtOH TMT saline vs norBNI t $34=2.62, \mathrm{p}=0.026]$. NorBNI did not alter sEPSC or sIPSC amplitude in stressed mice [Fig 4 Suppl 1E-F]. These ex-vivo experiments demonstrate that exposure to stress and EtOH induces KOR-mediated alteration of synaptic transmission in the BNST.

We then tested if dynorphin produced in the BNST played a role in behavioral changes following EtOH and TMT, as we have previously shown that BNST Pdyn can modulate synaptic transmission in the BNST (Crowley et al. 2016). Pdyn was deleted from the BNST using the $P d y n^{l o x / l o x}$ mouse line (Bloodgood et al. 2020) via AAV Cre-GFP microinfusions [Fig 5A-B, Fig 5 Suppl 1]. Pdyn deletion in the BNST did not alter EtOH consumption [Fig 5C-D; Time main effect $\mathrm{F}_{17,323}=3.28, \mathrm{p}=0.0095$; Cumulative EtOH drinking $(\mathrm{g} / \mathrm{kg})$ per group: $\mathrm{t}_{19}=0.23, \mathrm{p}=0.8181$ ] or preference [Fig 5E-F; Time main effect $\mathrm{F}_{17,323}=4.09$, $\mathrm{p}=0.0019$; average EtOH preference per group: $\left.\mathrm{t}_{19}=0.10, \mathrm{p}=0.9221\right]$. EtOH history moderately augmented distance traveled in the TMT 
test [Fig 5H; EtOH main effect $\mathrm{F}_{1,37}=6.20, \mathrm{p}=0.0174$ ], but Pdyn deletion was not a factor in this difference. EtOH mice with BNST Pdyn deletion suppressed EtOH-related increases in TMT contact [Fig 5G, Fig 5I; EtOH main effect $\mathrm{F}_{1,37}=7.31$, p=0.0103. GFP $\mathrm{H}_{2} \mathrm{O}$ vs EtOH $\mathrm{t}_{37}=2.93$, $\mathrm{p}=0.0347$ ], and they increased their burying behavior compared to control EtOH mice [Fig 5K;

interaction $\mathrm{F}_{1,37}=4.51, \mathrm{p}=0.0405$. EtOH GFP vs EtOH Cre-GFP $\left.\mathrm{t}_{37}=3.91, \mathrm{p}=0.0419\right]$. Importantly, there were no effects of Pdyn deletion in $\mathrm{H}_{2} \mathrm{O}$ drinkers on TMT response, nor were there effects in the elevated plus maze [Fig 5L-M]. These findings demonstrate a role for BNST Pdyn/KOR in regulating specific behavioral responses impaired by long-term EtOH drinking.

Given that we have previously reported increased glutamatergic transmission in the mPFC following acute TMT exposure (Hwa et al. 2019) and recent reports from the Radley lab indicated a key role in PFC inputs to the BNST in stress regulation, we next wanted to investigate if EtOH and TMT together may strengthen the functional connection between mPFC and BNST Pdyn neurons. To do this, we injected an AAV encoding channelrhodopsin (ChR2) into the mPFC of Pdyn-GFP mice [Fig 6A] and measured BNST cell responses to photostimulation of this pathway using slice electrophysiology [Fig 6B]. A large proportion of

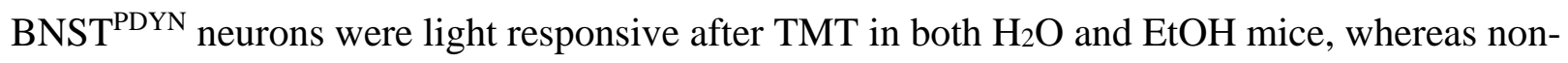
stressed $\mathrm{H}_{2} \mathrm{O}$ mice had mostly non-responsive cells [Fig 6C; $\mathrm{X}^{2}{ }_{3}=21.43$, $\mathrm{p}<0.0001$ ]. Similarly, EtOH mice had larger monosynaptic optically-evoked EPSC (oEPSC) amplitudes following TMT compared to $\mathrm{H}_{2} \mathrm{O}$ mice and non-stressed EtOH mice [Fig 6D; interaction $\mathrm{F}_{1,33}=4.74$, $\mathrm{p}=0.0367 ; \mathrm{H}_{2} \mathrm{O}$ non-stress $(\mathrm{NS}) \mathrm{vs} \mathrm{EtOH}+\mathrm{TMT}$ t33=3.70, $\mathrm{p}=0.0047 ; \mathrm{EtOH}$ NS vs EtOH + TMT $\left.\mathrm{t}_{33}=4.50, \mathrm{p}=0.0005\right]$, with no effects on paired pulse ratio [Fig 6E]. Both AMPA and NMDA peak amplitudes were greater in BNST ${ }^{\mathrm{PDYN}}$ EtOH TMT mice compared to unstressed EtOH mice and $\mathrm{H}_{2} \mathrm{O}$ mice [Fig 6F-G; AMPA peak amplitude: TMT main effect $\mathrm{F}_{1,34}=22.03$, p<0.0001; $\mathrm{H}_{2} \mathrm{O}$ 
NS vs EtOH + TMT t $t_{34}=4.28, p=0.0009 ; \mathrm{EtOH}_{\mathrm{NS}}$ vs EtOH + TMT $\mathrm{t}_{34}=4.82, \mathrm{p}=0.0002$. NMDA peak amplitude: TMT main effect $\mathrm{F}_{1,34}=12.09, \mathrm{p}=0.0148 ; \mathrm{H}_{2} \mathrm{O}$ NS vs EtOH + TMT $\mathrm{t}_{34}=3.13$, $\mathrm{p}=0.0213 ; \mathrm{EtOH}$ NS vs EtOH + TMT t34=3.27, $\mathrm{p}=0.0148]$. There was also an increase in the AMPA/NMDA ratio in the EtOH TMT mice [Fig 6H; TMT main effect $\mathrm{F}_{1,34}=8.12$, p=0.0074;

EtOH NS vs EtOH + TMT t $34=2.89, p=0.0132]$, suggesting alcohol drinking may prime the synapse for AMPA receptor recruitment, further contributing to aberrant glutamate signaling and stress reactions. In addition, the EtOH TMT mice were also more resistant to synaptic depression of oEPSC amplitude in response to repeated $1 \mathrm{~Hz}$ oEPSC pulses, suggesting alterations in shortterm plasticity [Fig 6I-L; interaction $\mathrm{F}_{27,351}=1.83, \mathrm{p}=0.0080$; Pulse $3:$ EtOH NS vs EtOH + TMT $\mathrm{t}_{22.81}=3.21, \mathrm{p}=0.0234 ; \mathrm{H}_{2} \mathrm{O}+\mathrm{TMT}$ vs EtOH $+\mathrm{TMT} \mathrm{t}_{18.81}=3.40, \mathrm{p}=0.0180 ;$ Pulse 4: EtOH NS vs $\left.\mathrm{EtOH}+\mathrm{TMT} \mathrm{t}_{23.99}=3.95, \mathrm{p}=0.0036\right]$. We next wanted to compare this mPFC-BNST pathway with another known glutamatergic input, so ChR2 was injected into the basolateral amygdala (BLA) in another group of Pdyn-GFP mice for slice recordings [Fig 6 Suppl 1A]. The BLA input to the BNST is large, as most cells were responsive to photostimulation in all groups [Fig 6 Suppl 1B]. In contrast to the mPFC-BNST pathway, EtOH drinking and TMT exposure did not affect BLA-BNST oEPSC amplitude [Fig 6 Suppl 1C], paired pulse ratio [Fig 6 Suppl 1D], AMPA peak amplitude [Fig 6 Suppl 1E], NMDA peak amplitude [Fig 6 Suppl 1F], or AMPA/NMDA ratio [Fig 6 Suppl 1G]. There were also no major group differences in BLABNST oEPSCs in response to repeated pulse trains [Fig 6 Suppl 1H-K].

To investigate the behavioral role of the PFC-BNST pathway in-vivo, we performed pathway-specific chemogenetic manipulations with designer receptors exclusively activated by designer drugs (DREADDs). A retrograde AAV containing cre recombinase was injected into the BNST, and an AAV containing cre-inducible hM4Di-mCherry or mCherry was injected into 
the mPFC of C57BL/6J mice [Fig 7A-B; Fig 7 Suppl 1]. Bath application of CNO on mPFC cell bodies infected with cre-inducible hM4Di-mCherry produced hyperpolarization of resting membrane potential [Fig 7C] and increased latency to fire action potentials [Fig 7D]. The inhibitory DREADD alone did not affect drinking behavior across the 6 weeks [Fig 7E] or short-

term drinking behavior when $\mathrm{CNO}$ was injected versus saline [Fig 7F-H]. When exposed to TMT, hM4Di-mediated inhibition of the mPFC-BNST pathway did not alter distance traveled [Fig 7J], but it did reduce contact with TMT in both $\mathrm{H}_{2} \mathrm{O}$ and EtOH mice [Fig 7I, Fig 7K; virus main effect: $F_{1,25}=5.37, p=0.0289$; no significant post-hoc differences]. Time spent in the far corners was not affected [Fig 7L]. mPFC-BNST inhibition also increased burying behavior in EtOH-drinking mice [Fig 7M; EtOH main effect: F1,25=13.80, p=0.001; virus main effect: $\mathrm{F}_{1,25}=16.47, \mathrm{p}=0.004 ; \mathrm{H}_{2} \mathrm{O}$ mCherry vs EtOH mCherry $\mathrm{t}_{25}=4.37, \mathrm{p}=0.0234 ;$ EtOH mCherry vs EtOH hM4Di t $25=4.72, p=0.0131]$. Time spent in the open and closed arms of the elevated plus maze were also not affected by the inhibitory DREADD [Fig 7N-O].

\section{Discussion}

Here, we have identified a causal role for the mPFC-BNST ${ }^{\mathrm{PDYN}}$ pathway in mediating alcohol-induced alterations in TMT predator odor-evoked stress responses. First, we identified $\mathrm{BNST}^{\mathrm{PDYN}}$ as a stress- and alcohol-sensitive population using immunohistochemistry and in situ hybridization. With whole cell patch clamp electrophysiology, we found that enhanced synaptic drive in $\mathrm{BNST}^{\mathrm{PDYN}}$ cells was reduced by KOR antagonism in stressed mice with a history of alcohol drinking. Finally, experiments with ex vivo optogenetics indicated that EtOH-drinking stressed mice had increased prefrontal cortical synaptic connectivity onto BNST ${ }^{\text {PDYN }}$ cells compared to stressed $\mathrm{H}_{2} \mathrm{O}$ drinkers and unstressed $\mathrm{EtOH}$ drinkers. We were able to manipulate 
EtOH-induced alterations in TMT stress reactions using BNST KOR antagonism, BNST Pdyn deletion, and PFC-BNST chemogenetic inhibition. Altogether, our findings indicate that engagement of Pdyn/KOR signaling in the BNST promotes an allostatic shift in stress-responses following EtOH drinking.

Previous articles from our laboratory have shown that wild-type and transgenic mice exhibit relatively modest intermittent EtOH drinking and preference (Bloodgood et al. 2020) compared to those reported in Hwa et al. (2011) publication, which was likely a results of varying vivarium conditions. However, mice in this study still achieved intoxicating blood EtOH concentrations, and this intermittent schedule may be favorable over drinking levels in continuous two-bottle choice access (Yu et al. 2019). In our hands, six weeks of intermittent access to EtOH affected behavioral responses to TMT predator odor. We interpret the EtOHinduced lack of avoidance of the predator odor as a maladaptive reaction to an innately stressful stimulus. While control mice displayed an array of stress behaviors in response to TMT (i.e. freezing, grooming, stretch-attend, etc.), a lack of burying was a prominent behavioral feature of $\mathrm{EtOH}$ mice. Burying in response to an immediate threat is commonly interpreted as an innate, active coping behavior in rodents (De Boer and Koolhaas, 2003). While EtOH mice also showed increased anxiety-like behavior in the elevated plus maze during protracted withdrawal, this group difference was eliminated following TMT exposure, as seen in our control drug/virus experiments after BNST norBNI, Pdyn deletion, and mPFC-BNST inhibition, suggesting longlasting impact of TMT on performance in the elevated plus maze.

Using converging approaches of intra-BNST norBNI infusions and genetic deletion of $\mathrm{BNST}^{\mathrm{PDYN}}$ using a floxed mouse line, we show that reducing Pdyn/KOR signaling at the pre- or 
post-synaptic level, respectively, normalizes alcohol-induced impairments in TMT behavioral responses during protracted abstinence. These results are in line with literature showing KOR antagonists can block anxiety-like behaviors precipitated by acute withdrawal from alcohol vapor (Valdez and Harshberger 2012, Rose et al. 2016) and suppress alcohol self-administration in post-dependent rats (Walker and Koob 2008, Schank et al. 2012, Kissler et al. 2014). KORs in the BNST appear to be particularly important in mediating interactions between stress and alcohol drinking, as BNST norBNI attenuates stress-induced alcohol seeking (Lê et al. 2018) and reduces alcohol withdrawal-induced 22-kHz ultrasonic vocalizations (Erikson et al. 2018). While this previous research has established that there is critical involvement of this stress peptide system in promoting acute alcohol withdrawal behaviors, we demonstrate here that KOR is still engaged in protracted abstinence, particularly during episodes of high stress exposure. Taken together, this body of evidence suggests that KOR signaling in the BNST is a critical pharmacological target for treatment of alcohol use disorders.

Our findings using c-Fos immunolabeling show that $\mathrm{BNST}^{\mathrm{PDYN}}$ cells are synergistically engaged in responses to stressors in EtOH-drinking mice. This complements existing c-Fos work in the BNST after TMT predator odor exposure (Day et al. 2004, Asok et al. 2013, Janitzky et al. 2015) while newly connecting the Pdyn population with changes in stress responses following a history of EtOH drinking. As we were using a GFP reporter line to determine Pdyn-containing neurons, we also thought it important to measure Pdyn and Oprk1 expression using fluorescence in situ hybridation. We observed that there was greater Pdyn content in EtOH mice, specifically a significant increase of Pdyn intensity and a trend towards Pdyn number. This suggests that increased c-Fos and Pdyn co-localization after EtOH exposure and stress could be due to the emergence of a larger pool of Pdyn neurons. Future studies should measure real-time 
engagement of BNST ${ }^{\mathrm{PDYN}}$ neurons during TMT exposure using fiber photometry, as specific subpopulation of BNST neurons are known to exhibit TMT-elicited calcium transients (Giardino et al. 2018).

Glutamatergic contribution to stress-enhanced signaling in BNST ${ }^{P D Y N}$ neurons

5 After assessing population activity of BNST PDYN/KOR after EtOH and stress and the contributions of this population to drinking-induced alterations in behavior, we performed synaptic transmission experiments on $\mathrm{BNST}^{\mathrm{PDYN}}$ neurons during protracted abstinence from EtOH. In addition, non-stressed intermittent EtOH mice displayed modestlyincreased sIPSC frequency in $\mathrm{BNST}^{\mathrm{PDYN}}$ cells. While some studies from our laboratory have reported increased sIPSC frequency in the BNST $24 \mathrm{hr}$ after drinking in monkeys (Pleil et al. 2015), others have found increased sEPSC/sIPSC ratios in C57BL/6J mice $48 \mathrm{hr}$ after ethanol vapor (Pleil et al. 2016) These differences are likely the result of cell-type specific population targeting, variations in drinking/exposure protocols, and withdrawal time points. During protracted abstinence, there were no apparent synaptic transmission differences between withdrawn mice and controls, although previous reports have found increased sEPSC frequency at this time point in female drinkers in a BNST CRF population (Centanni et al. 2019). Rather, we found that TMT exposure increased glutamatergic transmission in $\mathrm{BNST}^{\mathrm{PDYN}}$ neurons after EtOH and TMT, suggesting enhanced glutamatergic activity across the region. While $\mathrm{BNST}^{\mathrm{PDYN}}$ synaptic drive did not differ between stressed $\mathrm{H}_{2} \mathrm{O}$ and $\mathrm{EtOH}$ mice, differences in transmission were revealed during $\mathrm{KOR}$ blockade with norBNI pretreatment. Altogether, while other studies have found that chronic EtOH exposure and withdrawal can impact BNST spontaneous glutamatergic and NMDAR function (Kash et al. 2009, Wills et al. 2012, McElligott and Winder 2009), our findings are the 
first to highlight plastic shifts in response to stressors and identify pathway-specific alterations in neuropeptide signaling.

\section{EtOH and stress interact revealing synaptic plasticity from cortical input}

The mPFC, among other brain regions, is a known source of increased glutamatergic signaling onto BNST neurons. Previous work in the lab found that both central amygdala (CeA) and basolateral amygdala (BLA) inputs to the BNST are KOR-sensitive, but mPFC inputs are KOR-insensitive (Crowley et al. 2016). Notably, photostimulation of BLA inputs promotes anxiolysis in alcohol-naïve mice (Crowley et al. 2016). Taken together, these findings suggest a model in which increased activity of $\mathrm{BNST}^{\mathrm{PDYN}}$ neurons promote release of Pdyn, which in turn inhibit amygdala inputs to the BNST to promote inereased engagement of mPFC glutamate signaling. We have previously identified PL layer 2/3 neurons as a population engaged in response to acute TMT using a combination of slice physiology and immunohistochemical approaches (Hwa et al. 2019), providing converging data for engagement of this pathway by this specific aversive stimulus. However, while Pdyn/KOR signaling in the CeA appears to promote EtOH consumption (Bloodgood et al. 2020), Pdyn/KOR signaling in the BNST did not affect EtOH drinking in our study.

Our study provides valuable insight into how the synaptic strength of the mPFC to BNST $^{\text {PDYN }}$ pathway may be altered by combined exposure to EtOH and stress. Indeed, we found that a higher proportion of $\mathrm{BNST}^{\mathrm{PDYN}}$ neurons were light-responsive following stress or EtOH compared to $\mathrm{H}_{2} \mathrm{O}$ controls, suggesting that these stimuli increase connectivity between the mPFC and BNST ${ }^{\mathrm{DYN}}$ neurons. Taking into account the observed increases in oEPSC, AMPA, and NMDA amplitudes and AMPA/NMDA ratio after the combination of EtOH and TMT, it appears that $\mathrm{EtOH}$ exposure primes the synapse for aberrant responses to stressors under the control of a 
glutamatergic, mPFC-driven mechanism. Further, with repeated stimulation pulse trains, the EtOH TMT BNST ${ }^{\text {PDYN }}$ cells show reduced short-term depression, suggesting increased fidelity and short-term plasticity in this circuit. Again, this is in line with known chronic EtOH-induced glutamate plasticity in BNST cells (Wills et al. 2012). In contrast to the mPFC-BNST pathway, we observed no differences in the strength of BLA inputs to BNST ${ }^{\mathrm{PDYN}}$ neurons after EtOH and stress. Since there was a stress-EtOH interaction observed from the cortical projection, we wanted to examine how inhibition of this pathway could alter behavior. In an mPFC-BNST DREADD experiment, we found that chemogenetic inhibition also improved burying behavior in EtOH mice. This was specific to TMT behavior, as the manipulationdid not affect EtOH drinking or anxiety-like behavior in the elevated plus maze. These combined strategies of testing synaptic strength in slice and pathway-specific manipulation of behavior provide a mechanism for how long-term drinking and stress interact to dysregulate prefrontal inputs to BNST ${ }^{\mathrm{PDYN}}$ neurons.

\section{BNST circuitry control of stress behavior}

A recent paper from the Radley lab explored the role of the prelimbic (PL) mPFC to BNST pathway in stress-related behaviors in rats using optogenetics (Johnson et al. 2019). Activation of the PL to BNST circuit negatively correlated with freezing behavior, a measure of passive coping, in response to a shock prod, while photoinhibition increased freezing and decreased burying, a measure of active coping. Notably, they found that these behavioral effects were related to downstream control of the periaqueductal gray. An important future direction will be to assess the role of specific downstream projection targets of BNST Pdyn neurons, including the periaqueductal gray, in EtOH-induced alterations in TMT behavioral responses. It is also possible that excitatory local microcircuity in the BNST activates GABA neurons that inhibit 
ventral tegmental area GABA output signaling reward, which leads to anhedonia-like behavior and reduced stress responding. Our results illustrating aberrant responses to stress during protracted withdrawal from alcohol complement established research characterizing a more general role for the BNST in anxiety-related behaviors employing chemo- and optogenetics in mice (Kim et al. 2013, Jennings et al. 2013, Marcinkiewcz et al. 2016, Mazzone et al. 2018, Crowley et al. 2016).

\section{Conclusions}

Maladaptive responses to stress are a hallmark of alcohol use disorder, but the mechanisms that underlie this effect are not well characterized. Here we show that Pdyn/KOR signaling in the BNST is a critical molecular substrate disrupting stress-related behavioral responses following heavy alcohol drinking. Further, our findings suggest that increased corticolimbic connectivity may underlie this phenomenon; thus, altered mPFC-BNST connectivity could serve as a potential biomarker of negative outcomes in alcohol use disorder. Disentangling this imbalance of corticolimbic-driven stress neuropeptide signaling may lead to the development of novel therapeutics to enhance stress coping in persons with alcohol use disorder. 


\section{Materials and Methods}

Animals. Eight-week old male C57BL/6J mice (Jackson Laboratories, Bar Harbor, ME) were used for behavioral pharmacology experiments. To visualize Pdyn-expressing neurons, we generated a Pdyn-GFP reporter line by crossing preprodynorphin-IRES-Cre mice (Crowley et al.

2016, Bloodgood et al. 2020, Al-Hasani et al. 2015) (Pdyn-Cre) and Rosa26-flox-stop-L10-GFP reporter mice. For conditional knockout of BNST Pdyn, we used the Pdyn ${ }^{\text {lox/lox }}$ mouse line (Bloodgood et al. 2020). These mice were bred in the UNC facilities. All mice were grouphoused for at least 3 days before being singly housed in polycarbonate cages (GM500, Tecniplast, Italy) with a 12:12-h reversed dark-light cycle with lights off at 7:00am. Mice had unrestricted access to food (Prolab Isopro RMH 3000, LabDiet, St. Louis, MO) and $\mathrm{H}_{2} \mathrm{O}$. The UNC School of Medicine Institutional Animal Care and Use Committee approved all experiments. Procedures were conducted in accordance with the NIH Guidelines for the Care and Use of Laboratory Animals.

Intermittent EtOH Drinking. Mice were given $24 \mathrm{hr}$ access to a 20\% (w/v) EtOH solution and water on an intermittent schedule (Hwa et al. 2011). Two bottles were held in modified drinking spouts of plastic cage tops and weighed before and after daily EtOH access. A dummy cage without an animal was used to simulate fluid lost while positioning the bottles, so average fluid drip was subtracted from each mouse's daily drinking. Mice were tested for stress reactions to TMT during 7-10 day protracted abstinence after 6 weeks of intermittent drinking. Blood EtOH concentrations were measured in a subset of mice. Tail blood was collected after two hours of intermittent EtOH drinking, and then centrifuged at $3000 \mathrm{rpm}$ at $4^{\circ} \mathrm{C}$. Separated blood plasma was stored at $-20^{\circ} \mathrm{C}$ before analysis using the AM1 Analox Analyzer (Analox Intstruments Ltd., Lunenberg, MA). 


\section{Behavioral Assays after EtOH Drinking}

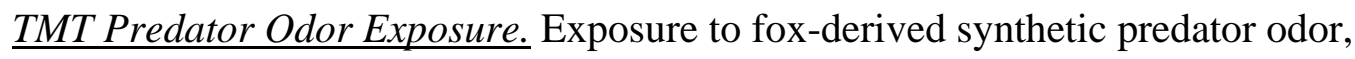
trimethylthiazoline (TMT), was performed in the home cage as previously described to elicit stress reactions in mice (Hwa et al. 2019). Animals were moved to a separate experimental room

for testing that included a fume hood and a large fan. Mice were tested one at a time for odor removal between trials. The lid of the home cage was removed for videorecording. Tests were conducted under dim lighting conditions, 15-20 lux. For a baseline pre-trial period, mice habituated to a cotton tip applicator held vertically in place for $10 \mathrm{~min}$ in the home cage. The TMT trial occurred when $2.5 \mu 1$ TMT was applied to the cotton tip followed by $10 \mathrm{~min}$ of behavioral observation. As a control odor, $2.5 \mu \mathrm{l}$ peanut oil (Harris Teeter, Carrboro, NC) was applied to the cotton tip in a separate group of mice. Duration of contact with the TMT object, time spent in the far corners of the cage, and distance traveled (sec) were recorded and quantified with Ethovision XT13 (Noldus, The Netherlands). Heatmaps were generated through Ethovision XT13. Burying was hand-scored using BORIS (Behavioral Observation Research Interactive Software) by a blind observer. The BORIS software also generated representative ethograms/Gantt plots of stress-related and exploratory behaviors, including duration and frequency of burying, freezing, grooming, rearing, stretch-attend, and walking.

Plasma Corticosterone Assay. To measure plasma corticosterone $30 \mathrm{~min}$ following TMT predator odor exposure, $5 \mu \mathrm{l}$ plasma samples were processed with a commercially available colorimetric ELISA kit (Arbor Assays, Ann Arbor, MI), according to the manufacturer's instructions. All samples were run in duplicates.

Elevated Plus Maze. Mice were placed into the center of an elevated plus maze $(75 \mathrm{~cm})$ and allowed to explore for 5 min (Bloodgood et al. 2020, Crowley et al. 2016, Mazzone et al. 
2018). Light levels in the open arms were approximately 15 lux. Duration of time spent in the open arms and closed arms were recorded and calculated by Ethovision XT13.

Stereotaxic Surgery. Adult mice (>8 weeks) were deeply anesthetized with 3-4\% isoflurane in oxygen and placed into a stereotaxic frame (Kopf Instruments, Tujunga, CA) while on a heated pad. Isoflurane anesthesia was maintained at 1-2\% during the remainder of the surgery. After sterilization with $70 \%$ ethanol and betadine, a scalp incision was made and burr holes were drilled above the target. A $1 \mu \mathrm{l}$ Neuros Hamilton syringe (Hamilton, Reno, NV) microinjected the virus or drug at a rate of $0.1 \mu \mathrm{l} / \mathrm{min}$. Coordinates for the dorsal BNST were AP $+0.30 \mathrm{~mm}$, $\mathrm{ML}+/-0.95 \mathrm{~mm}, \mathrm{DV}-4.35 \mathrm{~mm}$ from bregma. Coordinates for the mPFC were AP $+1.70 \mathrm{~mm}$, $\mathrm{ML}+/-0.30 \mathrm{~mm}, \mathrm{DV}-2.50 \mathrm{~mm}$ from bregma. Coordinates for the BLA were AP $-1.30 \mathrm{~mm}, \mathrm{ML}$ +/- 3.25 mm, DV -4.95 mm from bregma. Mice recovered for one week before testing. Drugs and Viral Vectors. $5 \mathrm{mg} / \mathrm{kg}$ norBNI (Cat no. 0347, Tocris) or saline was administered i.p., $1 \mathrm{ml} / 100 \mathrm{~g}, 16 \mathrm{hr}$ before testing to both EtOH and $\mathrm{H}_{2} \mathrm{O}$ mice. For intra-BNST norBNI microinfusions, $5 \mathrm{ug} / \mathrm{ul}$ norBNI was injected with $50 \mathrm{nl}$ AAV5-CamKII-eGFP to mark the injection site. Intra-BNST norBNI or PBS occurred 7 days prior to TMT testing. Both 16 hour and 7 day drug pretreatment minimized handling stress prior to the predator odor exposure and allowed for KOR antagonism instead of non-specific mu opioid antagonism that occurs initially post-injection. $P d y n^{l o x / l o x}$ mice received $300 \mathrm{nl}$ AAV5-CamKII-Cre-eGFP (UNC Vector Core, Lot 6450) and control AAV5-CamKII-eGFP (Lot 4621B) in the BNST. 300 nl AAV5-CamKIIahChR2(H134R)-mCherry-WPRE-hGH (Addgene, Lot CS1096) was injected into the mPFC or BLA of Pdyn-GFP mice for synaptic connectivity experiments in the BNST. C57BL/6J mice were injected with $300 \mathrm{nl} \mathrm{AAV8-hSyn-DIO-hM4D(Gi)-mCherry} \mathrm{(Addgene,} \mathrm{Lot} \mathrm{6048)} \mathrm{into} \mathrm{the}$ mPFC and AAV2retro-SL1-CAG-Cre into the BNST for mPFC-BNST inhibition. All 
intracranial injections were bilateral. $3 \mathrm{mg} / \mathrm{kg}$ clozapine $\mathrm{N}$-oxide (CNO; Hello Bio, Princeton, NJ) was dissolved in saline before i.p. administration, 1ml/100g, $20 \mathrm{~min}$ before testing. $\underline{c-F O S}$ Immunohistochemistry, Histology, and Microscopy. For c-Fos and histological verification, mice were deeply anesthetized with Avertin before transcardial perfusion with phosphate buffered saline and $4 \%$ paraformaldehyde. Brains were extracted 90 min following TMT exposure for c-Fos, cryoprotected, and then sliced at $45 \mu \mathrm{m}$ on a Leica $1200 \mathrm{~S}$ vibratome. Coronal sections of the Pdyn-GFP mice were stained for $c$-Fos immunofluorescence to visualize colocalization of Pdyn-containing (GFP) and c-Fos expressing cells. The immunofluorescence protocol for $c$-Fos was performed according to previous studies (Hwa et al. 2019) using tyramine signal amplification (TSA). After PBS washes, 50\% methanol, and 3\% hydrogen peroxide, tissue was incubated in blocking buffer with $0.3 \%$ Triton X-100 and 1\% bovine serum albumin for 60 min. Slices were then incubated at $4^{\circ} \mathrm{C}$ for $48 \mathrm{hr}$ in blocking buffer containing a rabbit anti-c-Fos antibody (1:3000, ABE457, Millipore, Bellerica, MA). After washes in TNT (0.1 M Tris-HCl, $0.15 \mathrm{M} \mathrm{NaCl}, 3 \%$ TritonX-100) and TNB (0.1 M Tris-HCl, 0.15 M NaCl, 0.5\% Perkin Elmer blocking reagent) buffer, slices were incubated in a goat anti-rabbit horse radish peroxidaseconjugated IgG (1:200, NEF812001EA, PerkinElmer, Waltham, MA) for 30 min. After TNT washes, tissue was processed using a TSA kit with Cy3-tyramide (1:50, PerkinElmer, Waltham, MA) for $10 \mathrm{~min}$. For the mPFC-BNST chemogenetic inhibition experiment, we enhanced the mCherry signal in the mPFC cell bodies and BNST terminals using a similar immunofluorescence protocol. After PBS washes, 3\% hydrogen peroxide, PBS washes, and 30 min in $0.5 \%$ Triton $X-100$, tissue was incubated in $0.1 \%$ Triton $X-100,10 \%$ normal donkey serum, and $1 \%$ bovine serum albumin for $60 \mathrm{~min}$. Slices were then incubated at $4^{\circ} \mathrm{C}$ for $24 \mathrm{hr}$ in blocking buffer containing a chicken anti-mCherry antibody (1:500, ab205402, Abcam, 
Cambridge, MA). After PBS washes, tissue underwent secondary incubation for $2 \mathrm{hr}$ at room temperature in PBS containing Alexa Fluor 488 donkey anti-chicken (1:200, Jackson ImmunoResearch Laboratories, Inc. West Grove, PA).

For placement verification, viral injection sites were verified using a wide-field epifluorescent microscope (BX-43, Olympus, Waltham, MA). For quantification of c-Fos immunofluorescence, slices were imaged on a Zeiss 800 laser scanning confocal microscope (Carl Zeiss, Germany) and analyzed with Zeiss Zen 2 Blue Edition software. Using the Image Analysis Wizard in the Zen Blue software, Pdyn-GFP cells were identified as the parent classifier, and c-Fos Cy3-labeled cells were identified as the child classifer. Automatic segmentation parameters were identical for each image within each new frame drawn to delineate the dorsal BNST. Pdyn-GFP cells, c-Fos cells, and c-Fos cells nested within Pdyn-GFP cells were automatically counted for each image. Four coronal brain sections containing the bilateral BNST were stained, imaged, and analyzed for each animal.

For in situ hybridization, brains were extracted 30 min following TMT exposure under isoflurane anesthesia. Tissue was flash frozen on dry ice for $15 \mathrm{~min}$ and stored at $-80^{\circ} \mathrm{C}$ until sectioned for in situ hybridization. $18 \mu \mathrm{m}$ coronal slices containing the BNST were made on the Leica CM 3050S cryostat (Leica Biosystems, Nussloch, Germany) at $-20^{\circ} \mathrm{C}$, mounted directly onto microscope slides, and stored at $-80^{\circ} \mathrm{C}$. In situ was performed according to the manufacterer's protocol for fresh frozen tissue sections (RNAscope Fluorescent Multiplex Assay; ACDbio, Newark, CA) with the following exceptions. PBS washes following tissue fixation were extended to $5 \mathrm{~min}$ each and protease treatment was shortened to $15 \mathrm{~min}$. Probes utilized were RNAscope Probe-Mm-Oprk1 (Cat no 316111) and RNAscope Probe-Mm-Pdyn (Cat no 318771). Slides were incubated with DAPI, coverslipped with ProLong Gold (Life 
Technologies), and imaged on a Zeiss 800 laser scanning confocal microscope. ImageJ was used to count mean intensity of fluorescence for Pdyn (550 channel) and Oprk (647 channel), and the cell counter plug-in was used to hand count Pdyn-positive neurons. After verification with DAPI, cells labeled with at least 3 puncta were counted as containing Pdyn mRNA. Hand counts were tabulated by a blind observer.

Slice Electrophysiology. Ninety minutes following TMT, during 7-10 day protracted withdrawal, mice were sacrificed via deep isoflurane anesthesia, and coronal brain slices containing the BNST were collected according to standard laboratory protocols (Hwa et al. 2019, Crowley et al. 2016, Bloodgood et al. 2020). Whole-cell voltage-clamp electrophysiological recordings were performed in dorsal BNST ${ }^{\text {PDYN }}$ cells. Pdyn-GFP-containing cells were selected based on visualization using a $470 \mathrm{~nm}$ LED and GFP fillter. The effects of EtOH and TMT on basal synaptic transmission were assessed in voltage clamp by adjusting the membrane potential and using a cesium methanesulfonate-based intracellular solution (135 mM cesium methanesulfonate, $10 \mathrm{mM} \mathrm{KCl,} \mathrm{10mM} \mathrm{HEPES,} 1$ mM MgCl2, 0.2 mM EGTA, 4 mM MgATP, $0.3 \mathrm{mM}$ GTP, $20 \mathrm{mM}$ phosphocreatine, pH 7.3, 285-290 mOsmol). Lidocaine n-ethyl bromide (1 $\mathrm{mg} / \mathrm{ml}$ ) was included in the intracellular solution to block postsynaptic sodium currents. Neurons were held at $-55 \mathrm{mV}$ to assess glutamatergic synaptic transmission. In the same cell, neurons were held at $+10 \mathrm{mV}$ to assess GABAergic synaptic transmission. Fluctuations in current were used to determine spontaneous post-synaptic current (sEPSC or sIPSC) frequency and amplitude, as well as to calculate sEPSC/sIPSC ratios. Synaptic transmission experiments in BNST ${ }^{\text {PDYN }}$ cells were also performed in animals that received $5 \mathrm{mg} / \mathrm{kg}$ norBNI i.p. $16 \mathrm{hr}$ prior to TMT. Electrophysiological recordings were then analyzed using Clampfit 10.7 software (Molecular Devices, Sunnyvale, CA). 
For ex-vivo optogenetic experiments, tissue was evaluated for light-evoked action potentials in the mPFC. Brains were discarded and not used for further experimentation if injection sites were missed or if action potentials were not present. A blue LED (470 nm, CoolLed) was used to optically stimulate release from channelrhodopsin (ChR2)-containing

fibers (Crowley et al. 2016). Picrotoxin (25 uM), tetrodotoxin (500 nM), and 4-AP (200 uM) were added to the aCSF to isolate monosynaptic oEPSCs with cells held at $-70 \mathrm{mV}$. The intracellular solution was cesium gluconate (117 mM D-gluconic acid and cesium hydroxide, 20 mM HEPES, 0.4 mM EGTA, 5 mM tetraethyl ammonium chloride, 2 mM MgCl26H2O, 4 mM Na2ATP, 0.4 Na2GTP, pH 7.3, 287-292 mOsmol). oEPSC amplitude (pA) was the first peak of the paired pulse ratio with a $50 \mathrm{~ms}$ interstimulus interval. Paired pulse ratio was calculated as the second peak amplitude divided by the first peak amplitude. Cells were held at $-70 \mathrm{mV}$ to isolate AMPAR-mediated current and at $+40 \mathrm{mV}$ for NMDAR-mediated current. In separate slices, ten 1,5 , and $10 \mathrm{~Hz}$ pulse trains were performed at $-55 \mathrm{mV}$ voltage clamp without the presence of ionotropic inhibitors with the cesium methanesulfonate internal solution. The nine subsequent amplitudes in the pulse train were normalized to the first peak.

For DREADD validation in slice, mPFC cell bodies were identified with mCherry expression. $10 \mu \mathrm{M}$ CNO (Hello Bio, Princeton, NJ) was bath applied for 10 min, and the resting membrane potential was monitored in voltage clamp. Action potential firing was assessed before and after $\mathrm{CNO}$ application using an increasing ramp protocol in current clamp.

Statistics. Time spent in contact with the TMT, far corners, and burying behavior in seconds (s), and distance traveled $(\mathrm{cm})$ were analyzed with two-way ANOVA with drug/virus and EtOH as factors. Post-hoc paired and unpaired t-tests were two-tailed and used where appropriate. In experiments where virus was injected before EtOH, cumulative 6-week alcohol intake and 
average ethanol preference were compared via t-test. BNST $c$-Fos, Pdyn-containing, and $c$-Fos and Pdyn colocalization were analyzed with two-way ANOVA with TMT exposure and EtOH as factors. With norBNI physiology, saline- and norBNI-injected stressed mice were compared in separate two-way ANOVA with drug and EtOH as factors. To compare proportion of lightresponsive cells per condition, a $\mathrm{X}^{2}$ test was performed. Furthermore, optically-evoked experiments (e.g. oEPSC amplitude) were analyzed with two-way ANOVAs comparing TMT and $\mathrm{EtOH}$ exposure. Pulse trains were analyzed with repeated measures two-way ANOVA across stimulus time and condition. Alpha was set to 0.05. Biological replicates throughout behavioral, immunohistochemical, and electrophysiological studies were combined. Statistical tests were analyzed with GraphPad Prism 8 (La Jolla,CA, USA).

\section{Acknowledgments}

Funding: This work was supported by the National Institutes of Health [grant numbers K99AA027576 (LSH), T32AA007573 (MEF), F32AA026485 (MMP), F31AA027129 (WY), R01AA019454 (TLK), U01AA020911 (TLK), and R01AA025582 (TLK)].

Author Contributions: LSH, SN, MEF, CS, EK, and RC performed and analyzed behavioral tests. LSH, SN, MMP, and DP assisted with electrophysiology experiments. WY, OH, and KB provided additional technical expertise. LSH and TLK conceptualized, designed the study, and wrote the manuscript. 


\section{References}

Asok, A., Ayers, L. W., Awoyemi, B., Schulkin, J., \& Rosen, J. B. (2013). Immediate early gene and neuropeptide expression following exposure to the predator odor 2, 5-dihydro-2, 4, 5trimethylthiazoline (TMT). Behavioural brain research, 248, 85-93.

Becker, H. C., Lopez, M. F., \& Doremus-Fitzwater, T. L. (2011). Effects of stress on alcohol drinking: a review of animal studies. Psychopharmacology, 218(1), 131.

Bloodgood, D. W., Hardaway, J. A., Stanhope, C. M., Pati, D., Pina, M. M., Neira, S., Desai, S., ... \& Kash, T. L. (2020). Kappa Opioid Receptor and Dynorphin Signaling in the Central Amygdala Regulates Alcohol Intake. Mol Psychiatry https://doi.org/10.1038/s41380-0200690-z.

Bruchas, M. R., Land, B. B., Lemos, J. C., \& Chavkin, C. (2009). CRF1-R activation of the dynorphin/kappa opioid system in the mouse basolateral amygdala mediates anxiety-like behavior. PloS one, 4(12), e8528.

Centanni, S. W., Morris, B.D., Luchsinger, J. R., Bedse, G., Fetterly, T. L., Patel, S., \& Winder,

15 D. G. (2019). Endocannabinoid control of the insular-bed nucleus of the stria terminalis circuit regulateshegative affective behavior associated with alcohol abstinence. Neuropsychopharmacology, 44(3), 526.

Crowley, N. A., Bloodgood, D. W., Hardaway, J. A., Kendra, A. M., McCall, J. G., Al-Hasani, R., ... \& Lowell, B. B. (2016). Dynorphin controls the gain of an amygdalar anxiety circuit. Cell reports, 14(12), 2774-2783.

Day, H. E., Masini, C. V., \& Campeau, S. (2004). The pattern of brain c-fos mRNA induced by a component of fox odor, 2, 5-dihydro-2, 4, 5-trimethylthiazoline (TMT), in rats, suggests both systemic and processive stress characteristics. Brain research, 1025(1-2), 139-151.

De Boer, S. F., Koolhaas, J. M. (2003). Defensive burying in rodents: ethology, neurobiology and psychopharmacology. Euro J Pharm, 463(1-3): 145-161.

Erikson, C. M., Wei, G., \& Walker, B. M. (2018). Maladaptive behavioral regulation in alcohol dependence: Role of kappa-opioid receptors in the bed nucleus of the stria terminalis. Neuropharmacology, 140, 162-173.

Fendt, M., Endres, T., \& Apfelbach, R. (2003). Temporary inactivation of the bed nucleus of the 30 stria terminalis but not of the amygdala blocks freezing induced by trimethylthiazoline, a component of fox feces. Journal of Neuroscience, 23(1), 23-28. 
Giardino, W. J., Eban-Rothschild, A., Christoffel, D. J., Li, S. B., Malenka, R. C., \& de Lecea, L. (2018). Parallel circuits from the bed nuclei of stria terminalis to the lateral hypothalamus drive opposing emotional states. Nature neuroscience, 21(8), 1084.

Gilpin, N. W., \& Weiner, J. L. (2017). Neurobiology of comorbid post-traumatic stress disorder and alcohol-use disorder. Genes, Brain and Behavior, 16(1), 15-43.

Heilig, M., Egli, M., Crabbe, J. C., \& Becker, H. C. (2010). Acute withdrawal, protracted abstinence and negative affect in alcoholism: are they linked? Addiction biology, 15(2), 169-184.

Hwa, L. S., Chu, A., Levinson, S. A., Kayyali, T. M., DeBold, J. F., \& Miczek, K. A. (2011). Persistent escalation of alcohol drinking in C57BL/6J mice with intermittent access to 20\% ethanol. Alcoholism: Clinical and Experimental Research, 35(14), 1938-1947.

Hwa, L. S., Neira, S., Pina, M. M., Pati, D., Calloway, R., \& Kash, T. L. (2019). Predator odor increases avoidance and glutamatergic synaptic transmission in the prelimbic cortex via corticotropin-releasing factor receptor 1 signaling. Neuropsychopharmacology, 44(4), 766.

Janitzky, K., Kröber A.. \& Schwegler, H. (2015). TMT predator odor activated neural circuit in C57BL/6J mice indicates TMT-stress as a suitable model for uncontrollable intense stress. Brain research, 1599, 1-8.

Jennings, J. H., Sparta, D. R., Stamatakis, A. M., Ung, R. L., Pleil, K. E., Kash, T. L., \& Stuber, G. D. (2013). Distinct extended amygdala circuits for divergent motivational states. Nature, 496(7444), 224.

Johnson, S. B., Emmons, E. B., Lingg, R. T., Anderson, R. M., Romig-Martin, S. A., LaLumiere, R. T., ... \& Radley, J. J. (2019). Prefrontal-bed nucleus circuit modulation of a passive coping response set. Journal of Neuroscience, 39(8), 1405-1419.

Kash, T. L. (2012). The role of biogenic amine signaling in the bed nucleus of the stria terminals in alcohol abuse. Alcohol, 46(4), 303-308.

Kash, T. L., Baucum II, A. J., Conrad, K. L., Colbran, R. J., \& Winder, D. G. (2009). Alcohol exposure alters NMDAR function in the bed nucleus of the stria terminalis. Neuropsychopharmacology, 34(11), 2420. 
Kim, S. Y., Adhikari, A., Lee, S. Y., Marshel, J. H., Kim, C. K., Mallory, C. S., ... \& Malenka, R. C. (2013). Diverging neural pathways assemble a behavioural state from separable features in anxiety. Nature, 496(7444), 219.

Kissler, J. L., Sirohi, S., Reis, D. J., Jansen, H. T., Quock, R. M., Smith, D. G., \& Walker, B. M. (2014). The one-two punch of alcoholism: role of central amygdala dynorphins/kappaopioid receptors. Biological psychiatry, 75(10), 774-782.

Koob, G. F. (2009). Brain stress systems in the amygdala and addiction. Brain research, 1293, $61-75$.

Koob, G., \& Kreek, M. J. (2007). Stress, dysregulation of drug reward pathways, and the transition to drug dependence. American Journal of Psychiatry, 164(8), 1149-1159.

Le Merrer, J., Becker, J. A., Befort, K., \& Kieffer, B. L. (2009). Reward processing by the opioid system in the brain. Physiological reviews, 89(4), $1379-1412$.

Lê, A. D., Funk, D., Coen, K., Tamadon, S., \& Shaham, Y. (2018). Role of א-opioid receptors in the bed nucleus of stria terminalis in reinstatement of alcohol seeking. Neuropsychopharmacology, 43(4), 838.

Lutz, P. E., \& Kieffer, B. E. (2013). Opioid receptors: distinct roles in mood disorders. Trends in neurosciences, 36(3), 195-206.

Marcinkiewcz, C. A., Mazzone, C. M., D’Agostino, G., Halladay, L. R., Hardaway, J. A., DiBerto, J. F., ... \& Tipton, G. J. (2016). Serotonin engages an anxiety and fearpromoting circuit in the extended amygdala. Nature, 537(7618), 97.

Mazzone, C. M., Pati, D., Michaelides, M., DiBerto, J., Fox, J. H., Tipton, G., ... \& Magness, S. T. (2018). Acute engagement of $\mathrm{G}$ q-mediated signaling in the bed nucleus of the stria terminalis induces anxiety-like behavior. Molecular psychiatry, 23(1), 143.

McElligott, Z. A., \& Winder, D. G. (2009). Modulation of glutamatergic synaptic transmission in the bed nucleus of the stria terminalis. Progress in Neuro-Psychopharmacology and Biological Psychiatry, 33(8), 1329-1335.

Noone, M., Dua, J., \& Markham, R. (1999). Stress, cognitive factors, and coping resources as predictors of relapse in alcoholics. Addictive Behaviors, 24(5), 687-693.

Pleil, K. E., Helms, C. M., Sobus, J. R., Daunais, J. B., Grant, K. A., \& Kash, T. L. (2016). Effects of chronic alcohol consumption on neuronal function in the non-human primate BNST. Addiction biology, 21(6), 1151-1167. 
Pleil, K. E., Lowery-Gionta, E. G., Crowley, N. A., Li, C., Marcinkiewcz, C. A., Rose, J. H., ... \& Kash, T. L. (2015). Effects of chronic ethanol exposure on neuronal function in the prefrontal cortex and extended amygdala. Neuropharmacology, 99, 735-749.

Rose, J. H., Karkhanis, A. N., Chen, R., Gioia, D., Lopez, M. F., Becker, H. C., .. \& Jones, S. R. (2016). Supersensitive kappa opioid receptors promotes ethanol withdrawal-related behaviors and reduce dopamine signaling in the nucleus accumbens. International Journal of Neuropsychopharmacology, 19(5).

Schank, J. R., Goldstein, A. L., Rowe, K. E., King, C. E., Marusich, J. A., Wiley, J. L., ... \& Heilig, M. (2012). The kappa opioid receptor antagonist JDTic attenuates alcohol seeking and withdrawal anxiety. Addiction biology, 17(3), 634-647.

Sinha, R., Fox, H. C., Hong, K. I. A., Hansen, J., Tuit, K., \& Kreek, M.J.(2011). Effects of adrenal sensitivity, stress-and cue-induced craving, and anxiety on subsequent alcohol relapse and treatment outcomes. Archives of general psychiatry, 68(9), 942-952.

Valdez, G. R., \& Harshberger, E. (2012). Kappa opioid regulation of anxiety-like behavior during acute ethanol withdrawal. Pharmacology Biochemistry and Behavior, 102(1), 4447.

Walker, B. M., \& Koob, G. F. (2008). Pharmacological evidence for a motivational role of $\kappa-$ opioid systems in ethanol dependence. Neuropsychopharmacology, 33(3), 643.

Wills, T. A., Klug, J. R., Silberman, Y., Baucum, A. J., Weitlauf, C., Colbran, R. J., ... \& Winder, D. G. (2012). GluN2B subunit deletion reveals key role in acute and chronic ethanol sensitivity of glutamate synapses in bed nucleus of the stria terminalis. Proceedings of the National Academy of Sciences, 109(5), E278-E287.

Yu, W., Hwa, L. S., Makhijani, V. H., Besheer, J., Kash, T. L. (2019). Chronic inflammatory pain drives alcohol drinking in a sex-dependent manner in C57BL/6J mice. Alcohol, 77, $135-145$. 


\section{Figure 1}
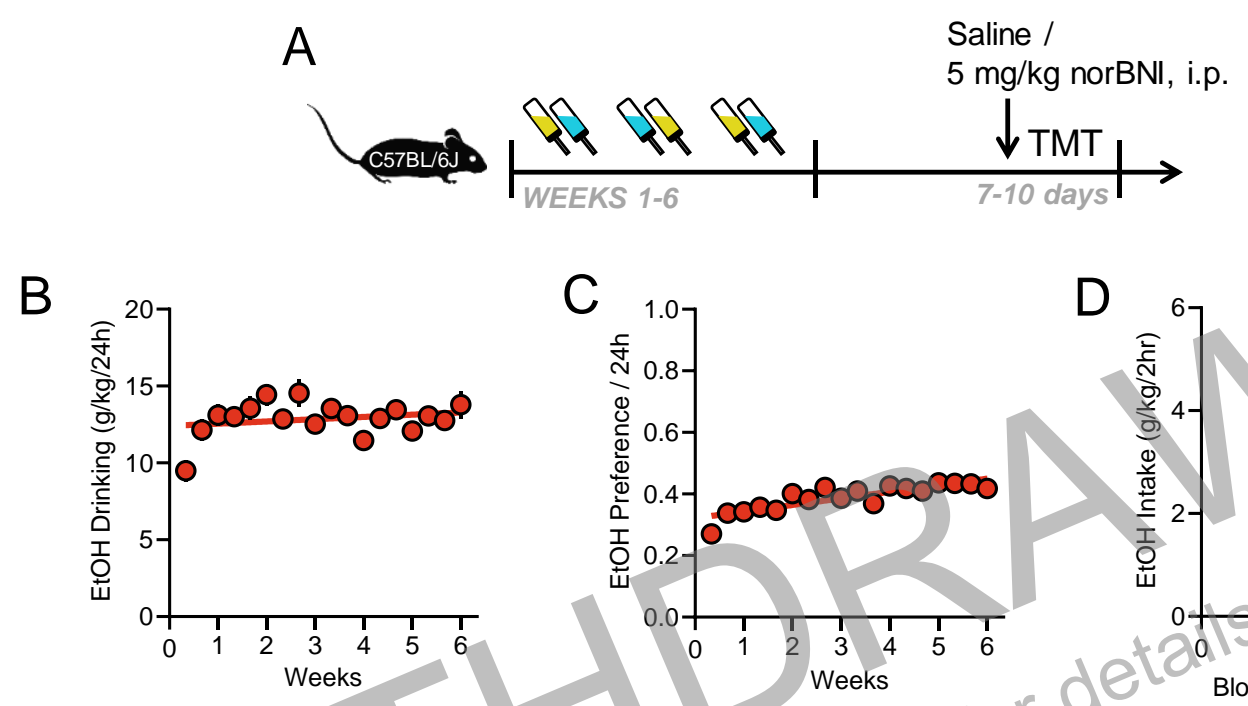

E
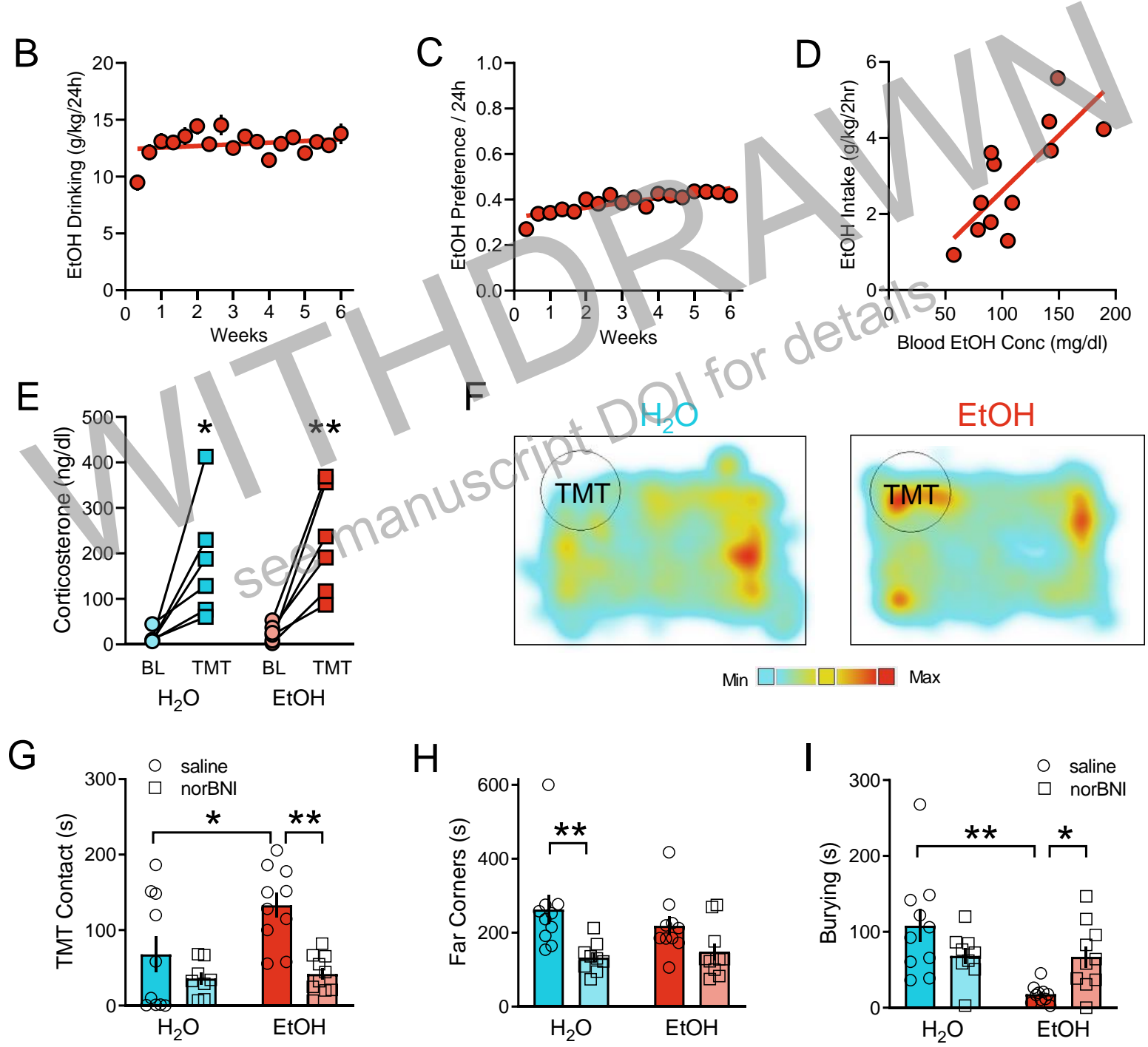

Figure 1. KOR regulation of responses to TMT predator odor after long-term alcohol drinking. A, Experimental protocol for $5 \mathrm{mg} / \mathrm{kg}$ i.p. KOR antagonist manipulation of predator odor behavior after intermittent EtOH. B, EtOH drinking (g/kg/24hr) and C, EtOH preference / 24hr of male C57BL/6J mice (n=46 mice). D, Blood EtOH concentrations ( $\mathrm{mg} / \mathrm{dl})$ correlated with EtOH intake $(\mathrm{g} / \mathrm{kg} / 2 \mathrm{hr})$ in a subset of mice. E, Plasma corticosterone (ng/dl) response $30 \mathrm{~min}$ after TMT exposure. F, Representative heatmaps of individual $\mathrm{H}_{2} \mathrm{O}$ (left) and $\mathrm{EtOH}$ (right) spatial location in the 10 min test. The circle indicates TMT location. Red color indicates maximum time spent. Aqua color indicates minimum time spent. Pretreatment with norBNI affected: G, TMT contact (sec), H, Time spent in the far corners (sec), and I, Burying (sec). $* \mathrm{p}<0.05, * * \mathrm{p}<0.01$ 
Figure 2

A

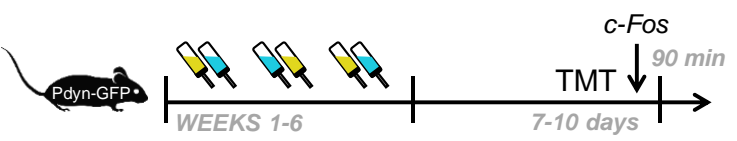

C

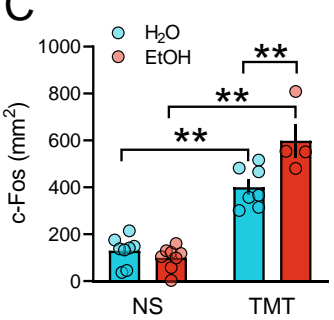

D

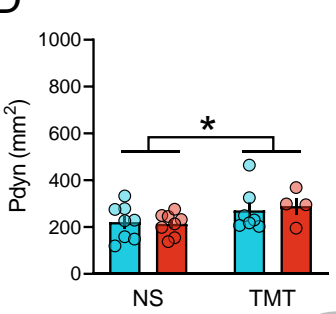

$\mathrm{E}$
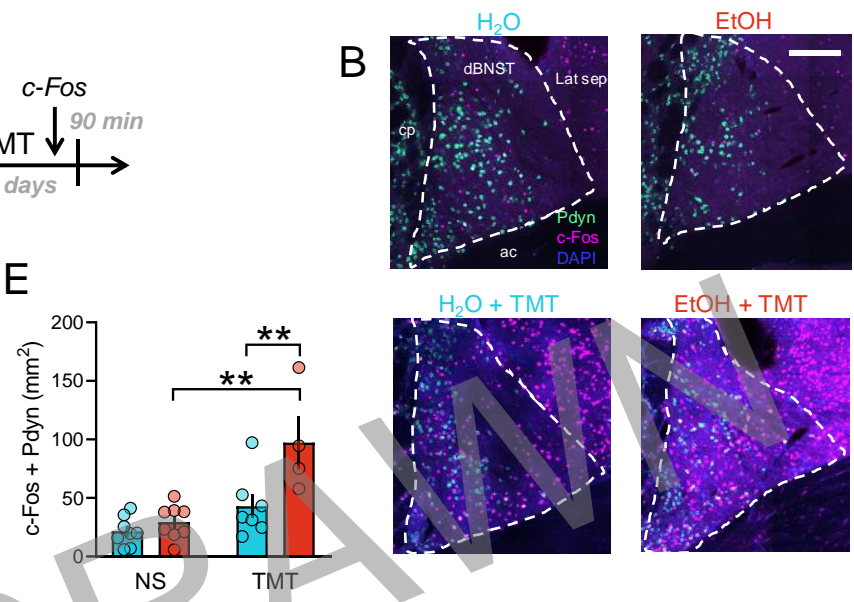

$\mathrm{EtOH}+\mathrm{TMT}$
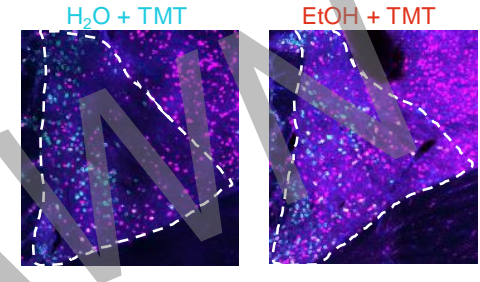

$\mathrm{H}_{2} \mathrm{O}+\mathrm{TMT}$

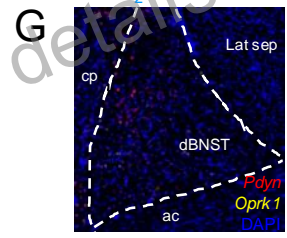

$1 \mathrm{~J}$
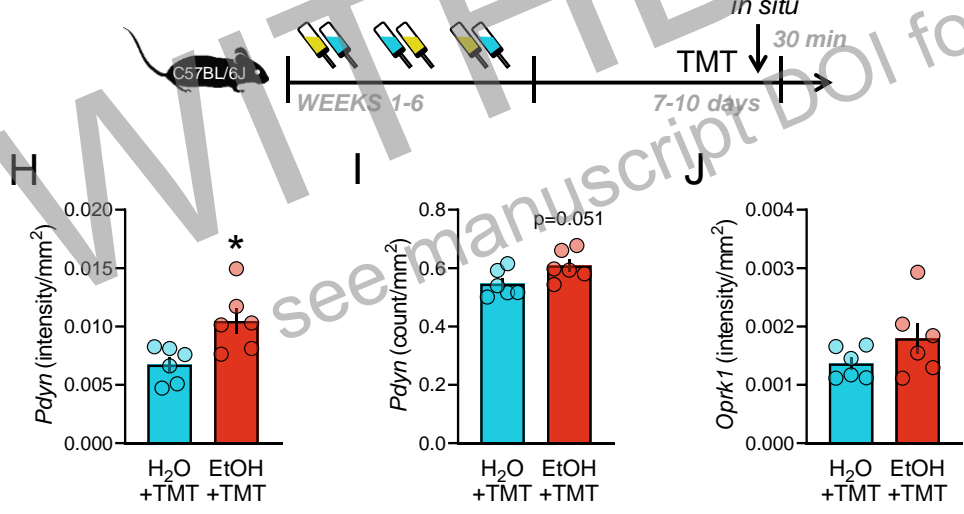

$\mathrm{H}_{2} \mathrm{O}+\mathrm{TMT}$

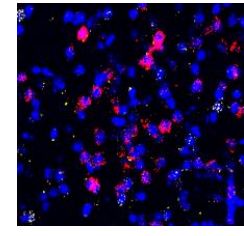

$\mathrm{EtOH}+\mathrm{TMT}$

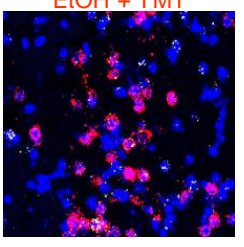

Figure 2. BNST as a critical site for prodynorphin neurons activated after stress during protracted withdrawal from alcohol. A, Schematic of obtaining BNST tissue for c-Fos immunohistochemistry 90 min post-TMT in Pdyn-GFP mice. B, Representative images of Pdyn (green) and c-Fos Cy3 immunostaining (pseudocolored purple) in $\mathrm{H}_{2} \mathrm{O}(\mathrm{n}=8)$, EtOH $(\mathrm{n}=8), \mathrm{H}_{2} \mathrm{O}+\mathrm{TMT}(\mathrm{n}=7)$, and EtOH + TMT $(\mathrm{n}=4)$ conditions. Scale bar is $200 \mu \mathrm{m} . \mathrm{cp}=$ caudate putamen, $\mathrm{ac}=$ anterior commissure, Lat sep $=$ lateral septum. C, BNST c-Fos quantification $\left(\mathrm{mm}^{2}\right)$. Aqua bars are $\mathrm{H}_{2} \mathrm{O}$, red bars are EtOH. D, Pdyn-GFP quantification $\left(\mathrm{mm}^{2}\right)$. E, Colocalization between c-Fos and Pdyn-GFP $\left(\mathrm{mm}^{2}\right)$. F, Schematic of obtaining BNST tissue for in situ hybridization $30 \mathrm{~min}$ post-TMT in C57BL/6J mice. G, BNST images of Pdyn (pseudocolored red) Oprk1 (pseudocolored yellow) mRNA expression in $\mathrm{H}_{2} \mathrm{O}(\mathrm{n}=6)$ and EtOH $(\mathrm{n}=6)$ mice after TMT. H, Pdyn (intensity $/ \mathrm{mm}^{2}$ ), I, pdyn (counts $/ \mathrm{mm}^{2}$ ), and J, Oprk1 (intensity/ $/ \mathrm{mm}^{2}$ ) are shown. ${ }^{*} \mathrm{p}<0.05$. $* * \mathrm{p}<0.01$. 


\section{Figure 3}
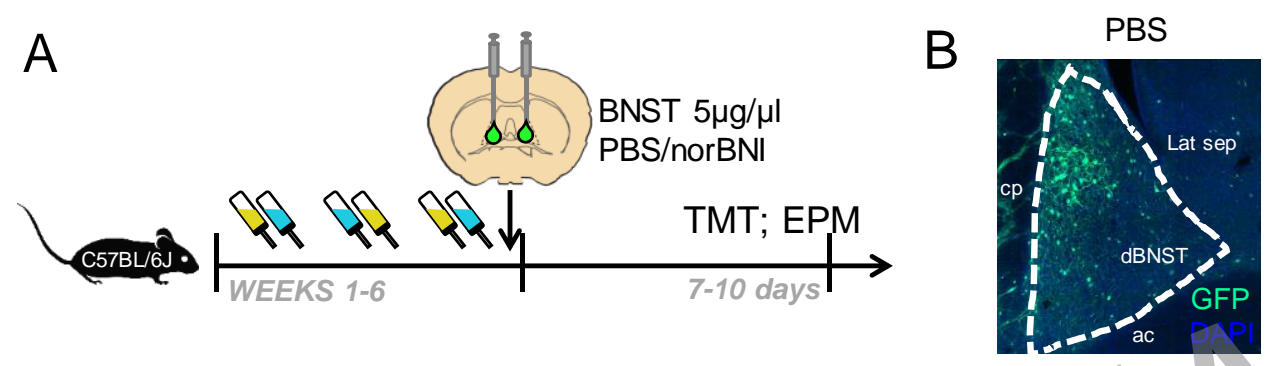

norBNI
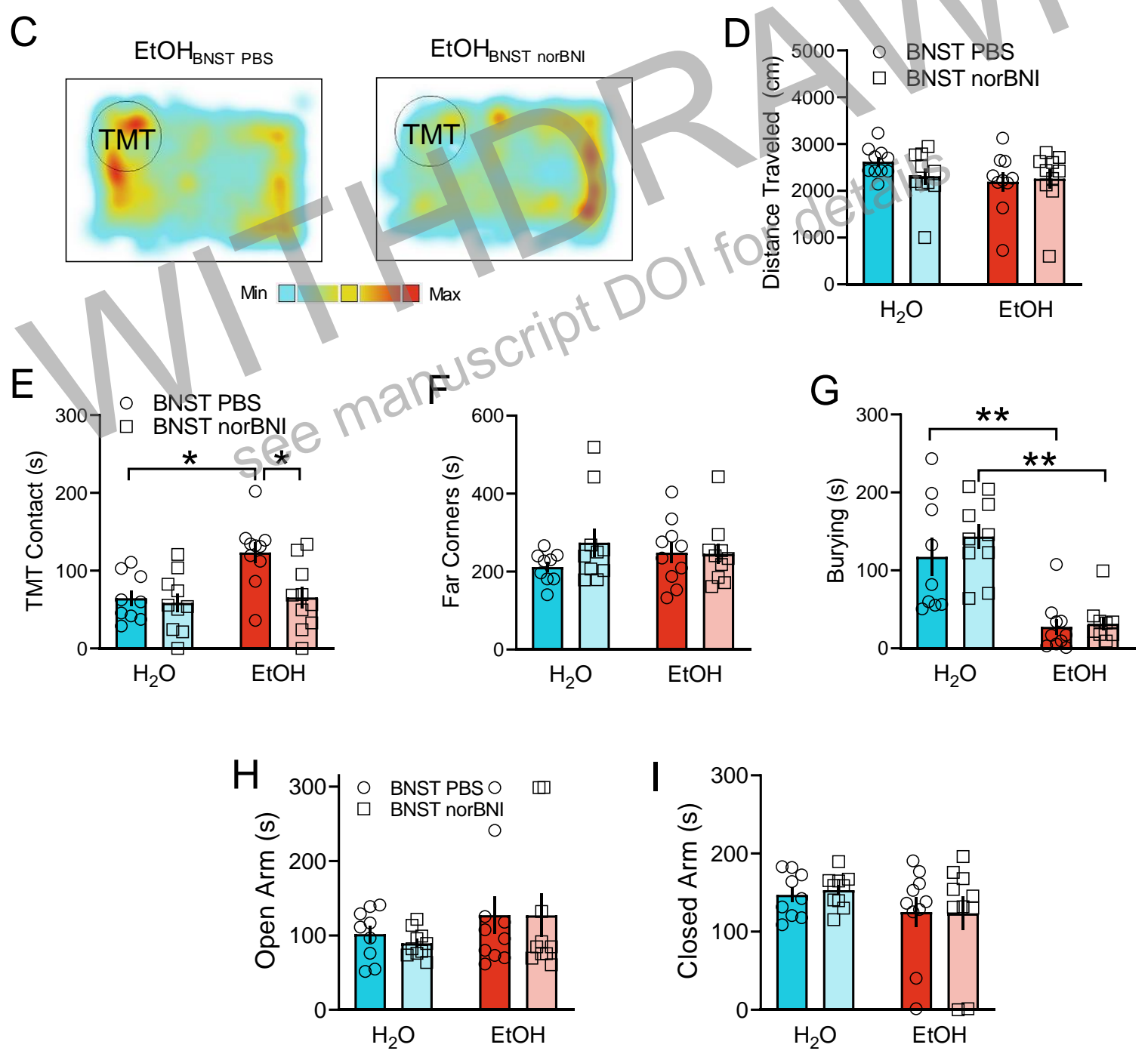

Figure 3. Role of BNST KOR in responses to predator odor after alcohol. A, Experimental design for 5 $\mu \mathrm{g} / \mu \mathrm{l}$ norBNI in the BNST. B, Representative images of BNST infusions of PBS $\left(\mathrm{n}=9 \mathrm{H}_{2} \mathrm{O}, \mathrm{n}=10 \mathrm{EtOH}\right)$ and norBNI $\left(n=10 \mathrm{H}_{2} \mathrm{O}, \mathrm{n}=10 \mathrm{EtOH}\right)$ marked with GFP. Scale bar indicates $200 \mu \mathrm{M}$. C, Representative heatmaps of TMT-induced activity with EtOH BNST PBS (left) and EtOH BNST norBNI (right). D, Distance traveled during the TMT test. E, TMT contact (sec), F, time spent in the far corners (sec), and G, burying (sec) during the TMT trial. Time spent in the $\mathbf{H}$, open arms (sec) and $\mathbf{I}$, closed arms (sec) of the elevated plus maze. ${ }^{*} \mathrm{p}<0.05 .{ }^{*} \mathrm{p}<0.01$. 


\section{Figure 4}

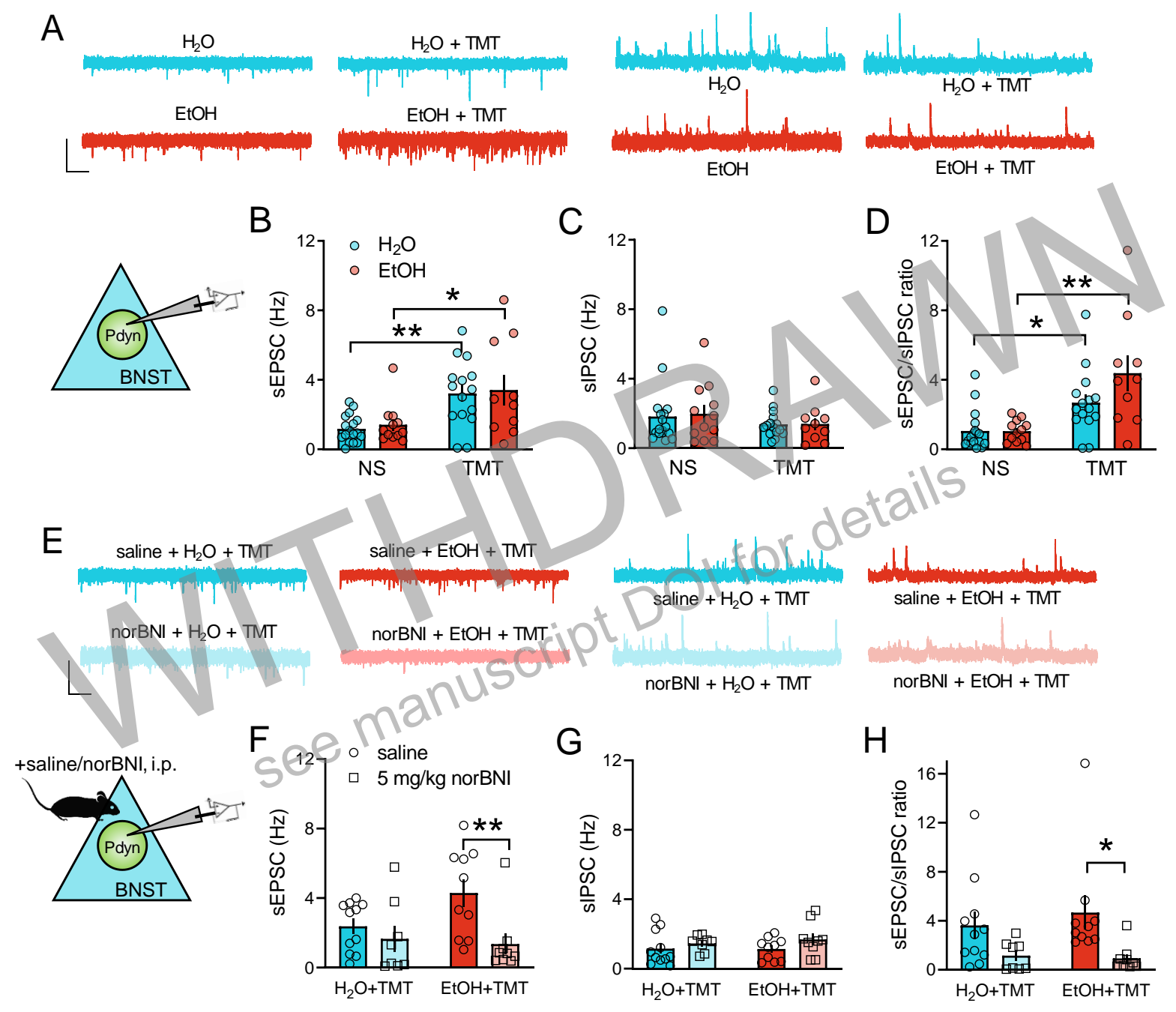

Figure 4. KOR regulation of increased synaptic transmission onto BNST Pdyn neurons after stress and EtOH. A, Representative traces of $\mathrm{BNST}^{\mathrm{PDYN}}$ cell synaptic transmission in $\mathrm{H}_{2} \mathrm{O}(\mathrm{n}=6,17$ cells), EtOH ( $\mathrm{n}=4$, 12 cells), $\mathrm{H}_{2} \mathrm{O}+$ TMT ( $\mathrm{n}=5,15$ cells), and $\mathrm{EtOH}+$ TMT ( $\mathrm{n}=4,10$ cells). Scale bar indicates $50 \mathrm{pA}$ height and $1 \mathrm{sec}$ time. Spontaneous excitatory post-synaptic currents (sEPSC) are on the left, and spontaneous inhibitory post-synaptic currents (sIPSC) are on the right. B, sEPSC frequency (Hz), C, sIPSC frequency $(\mathrm{Hz})$, and $\mathbf{D}$, sEPSC/sIPSC ratio in dorsal BNST Pdyn cells. E, Sample traces of BNST ${ }^{\text {PDYN }}$ cell synaptic transmission after $16 \mathrm{hr}$ pretreatment with $5 \mathrm{mg} / \mathrm{kg}$ norBNI or saline, i.p. Aqua is saline $+\mathrm{H} 2 \mathrm{O}+\mathrm{TMT}$ $\left(n=4,11\right.$ cells). Red is saline $+\mathrm{EtOH}+$ TMT $\left(n=4,10\right.$ cells). Light aqua is norBNI $+\mathrm{H}_{2} \mathrm{O}+$ TMT $(n=3,8$ cells). Light red is norBNI + EtOH + TMT ( $\mathrm{n}=3,9$ cells). Scale bar equals $50 \mathrm{pA}$ height and $1 \mathrm{sec}$ time. F, sEPSC frequency $(\mathrm{Hz})$. G, sIPSC frequency $(\mathrm{Hz}) . \mathbf{H}, \mathrm{sEPSC} / \mathrm{sIPSC}$ ratio. $* \mathrm{p}<0.05 . * * \mathrm{p}<0.01$. 
Figure 5
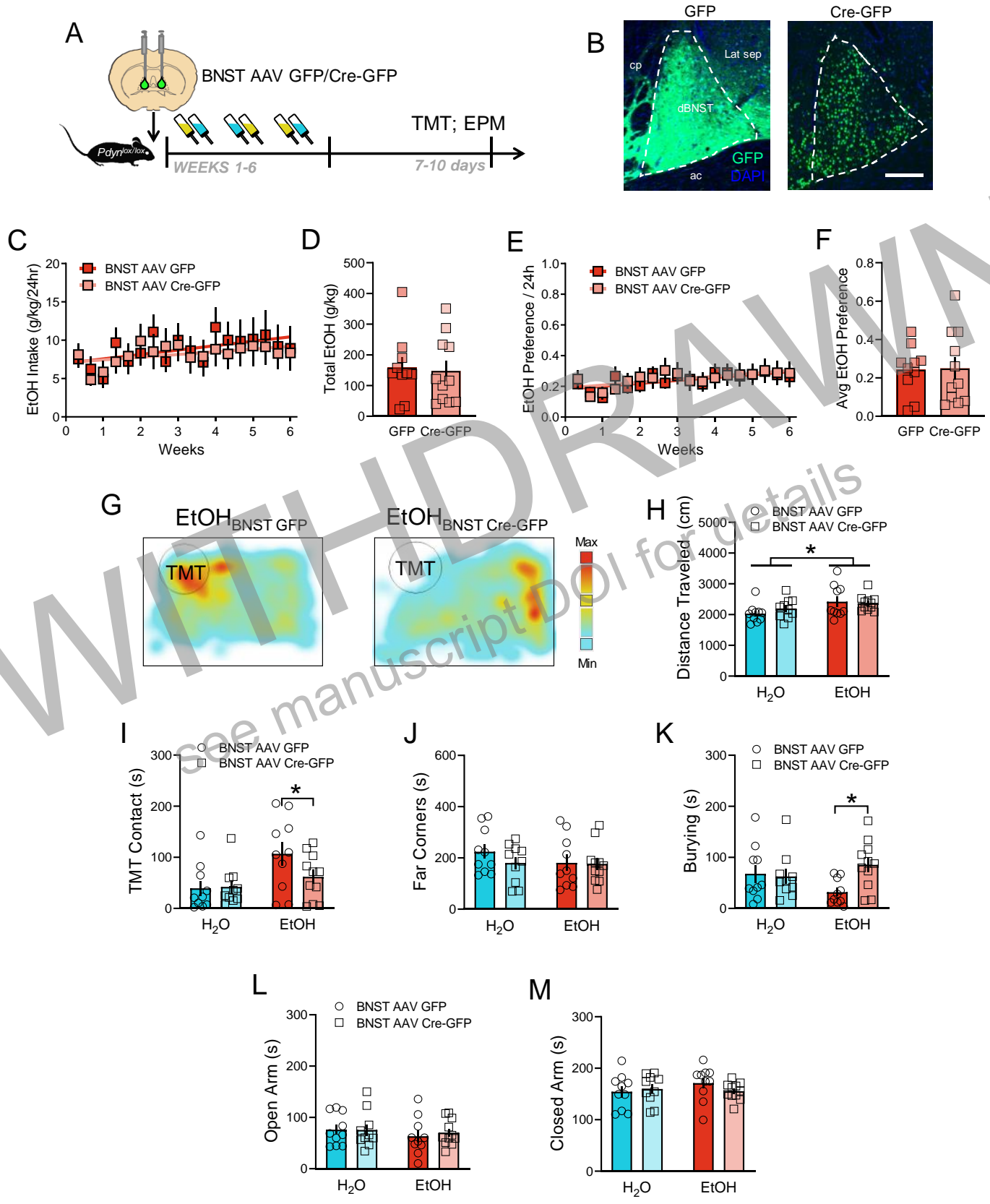

Figure 5. EtOH drinking and TMT responses after BNST Pdyn deletion. A, Time course of deletion of BNST Pdyn in $P d y n^{l o x / l o x}$ mice before EtOH and TMT. B, Images of AAV-GFP and AAV-Cre-GFP expression $\left(\mathrm{H}_{2} \mathrm{O}\right.$ GFP $\mathrm{n}=10$, Cre-GFP $\mathrm{n}=10$. EtOH GFP $\mathrm{n}=10$, EtOH Cre-GFP $\left.\mathrm{n}=11\right)$. Scale bar measures $200 \mu$ M. C, $P d y n^{l o x / l o x}$ mice EtOH drinking (g/kg/24hr) across 6 wks with BNST GFP (red) or Cre-GFP (light red). D, Cumulative EtOH drinking (g/kg) per group. J, $P d y n^{l o x / l o x}$ mice daily EtOH preference across 6 wks with BNST GFP (red) or Cre-GFP (light red). K, Average EtOH preference per group. G, Sample TMT heatmaps of EtOH BNST GFP (left) and EtOH BNST Cre-GFP (right) mice. In the TMT test, $\mathbf{H}$, distance traveled (cm), I, TMT contact, J, far corners (sec), and $\mathbf{K}$, burying (sec). In the elevated plus maze, duration in the $\mathbf{L}$, open arms (sec), and $\mathbf{M}$, closed arms ( $\mathrm{sec}$ ). ${ }^{*} \mathrm{p}<0.05$. 
Figure 6
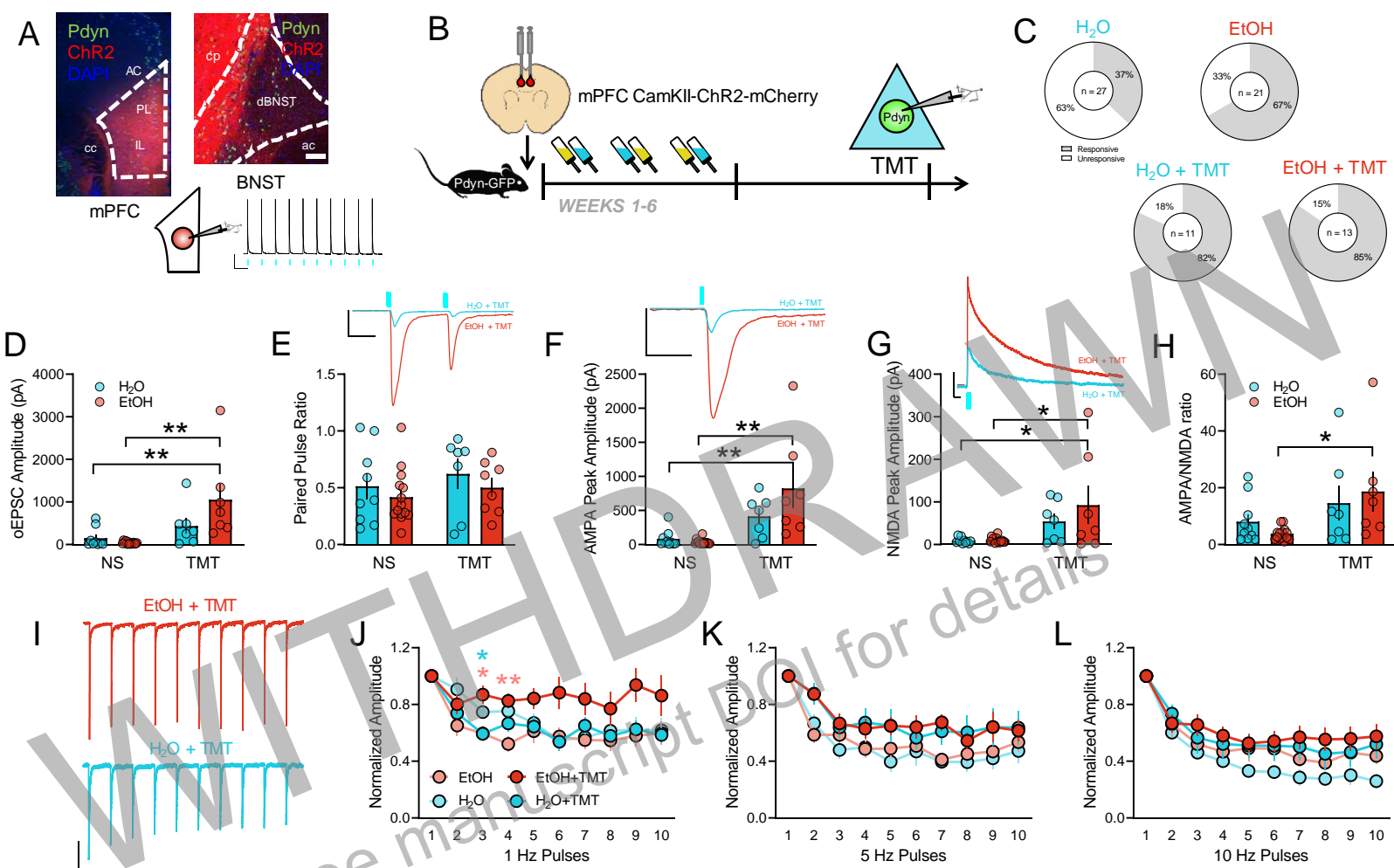

Figure 6. Cortical input onto BNST ${ }^{\mathrm{PDYN}}$ cells gates stress-enhanced glutamatergic plasticity after history of alcohol. A, Image of CamKII-ChR2-mCherry expression in the mPFC (left) and at BNST terminals (right). Pdyn-GFP cells are green. Inset photo scale bars measure $100 \mu \mathrm{m}$. Representative traces of optically-evoked mPFC action potentials at $1 \mathrm{~Hz}$. Blue rectangles indicate 470nm LED onset. Scale bar indicates $20 \mathrm{mV}$ and $1 \mathrm{sec}$. B, Experimental design testing synaptic connectivity of mPFC input to BNST $^{\text {PDYN }}$ cells using channelrhodopsin (ChR2) after EtOH and TMT. C, Proportions of light-responsive (white) and non-light-responsive (grey) BNST $^{\text {PDYN }}$ cells to optically-evoked EPSC in $\mathrm{H}_{2} \mathrm{O}(10 / 27$ responsive cells, $n=7)$, EtOH (14/21 responsive cells, $n=5), \mathrm{H}_{2} \mathrm{O}+$ TMT (9/11 responsive cells, $\left.n=4\right)$, and EtOH + TMT (11/13 responsive cells, $n=4)$ groups. $\mathbf{D}$, mPFC-BNST $^{\text {PDYN }}$ oEPSC amplitude (pA). E, Paired pulse ratio. Inset example traces of $\mathrm{H}_{2} \mathrm{O}+\mathrm{TMT}$ (aqua) and EtOH + TMT (red) with blue LED onset. Scale bar indicates $200 \mathrm{pA}$ height and $50 \mathrm{~ms}$ time. F, AMPA peak amplitude (pA). Inset AMPA traces of $\mathrm{H}_{2} \mathrm{O}+$ TMT (aqua) and EtOH + TMT (red) with blue LED onset. Scale bar indicates $200 \mathrm{pA}$ height and $50 \mathrm{~ms}$ time. G, NMDA peak amplitude (pA). Inset NMDA traces of $\mathrm{H}_{2} \mathrm{O}+$ TMT (aqua) and EtOH + TMT (red) with blue LED onset. Scale bar indicates $200 \mathrm{pA}$ height and $50 \mathrm{~ms}$ time. H, AMPA/NMDA ratio. I, Representative traces of $1 \mathrm{~Hz}$ pulse trains in EtOH + TMT (red) and $\mathrm{H}_{2} \mathrm{O}+\mathrm{TMT}$ (aqua) BNST ${ }^{\mathrm{PDYN}}$ cells. Scale bar indicates $200 \mathrm{pA}$ height and $1 \mathrm{sec}$ time. oEPSC normalized amplitude across $\mathbf{J}, 1 \mathrm{~Hz}, \mathbf{K}, 5 \mathrm{~Hz}$, and $\mathbf{L}, 10 \mathrm{~Hz}$ pulse trains. $* \mathrm{p}<0.05$. $* * \mathrm{p}<0.01$. 
Figure 7

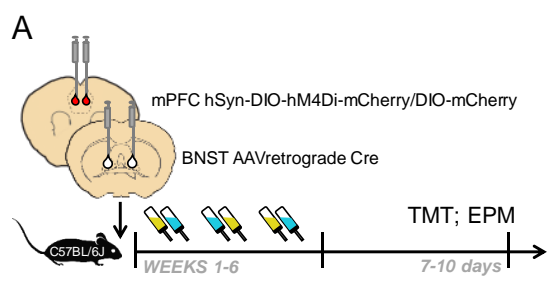

$\mathrm{E}$

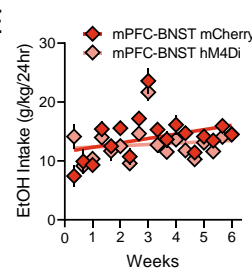

$\mathrm{EtOH}_{\text {mPFC-BNSTmCherry }}$
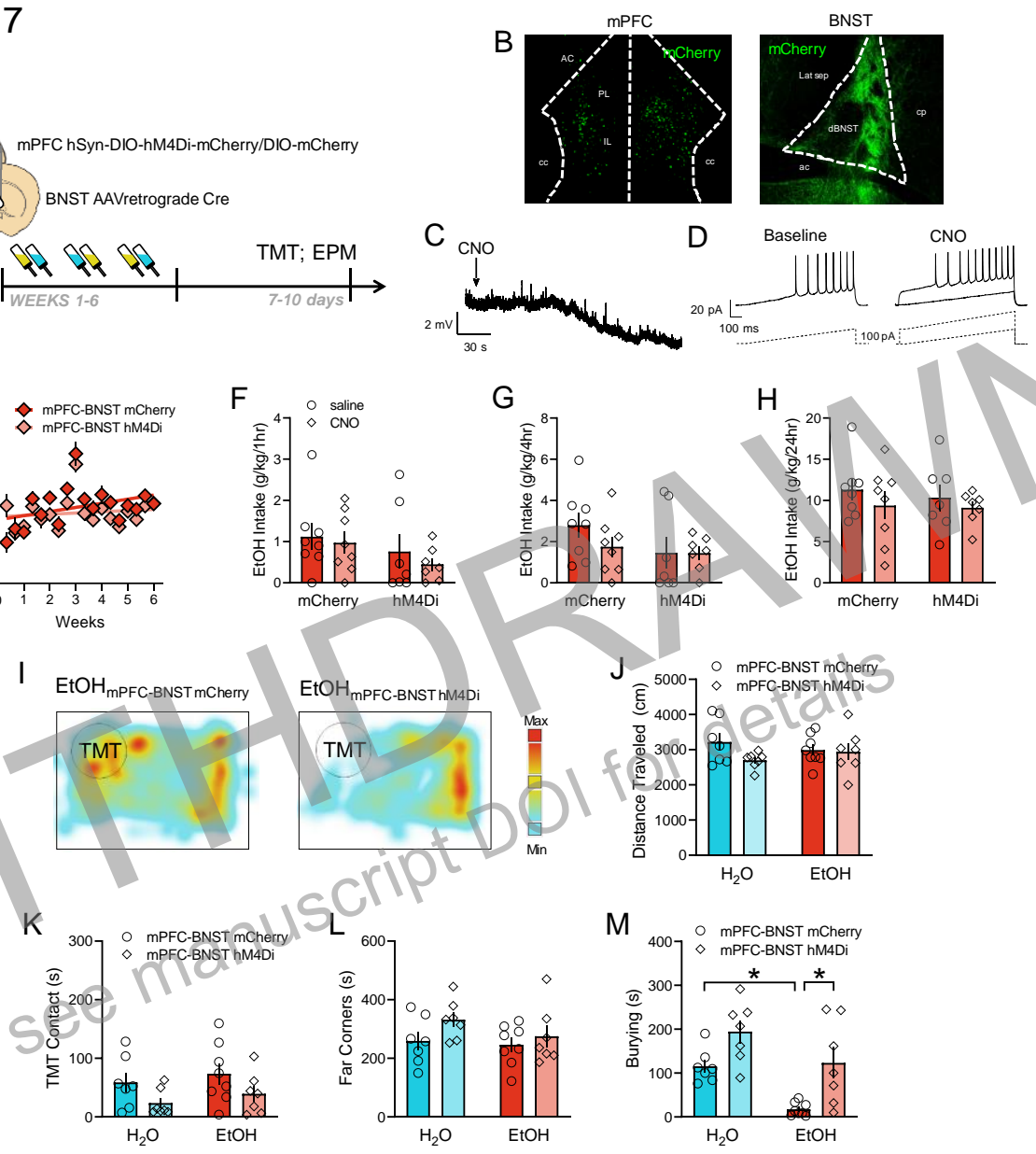

G

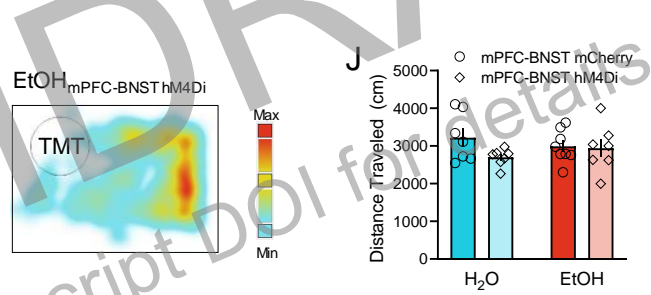

$\mathrm{H}$
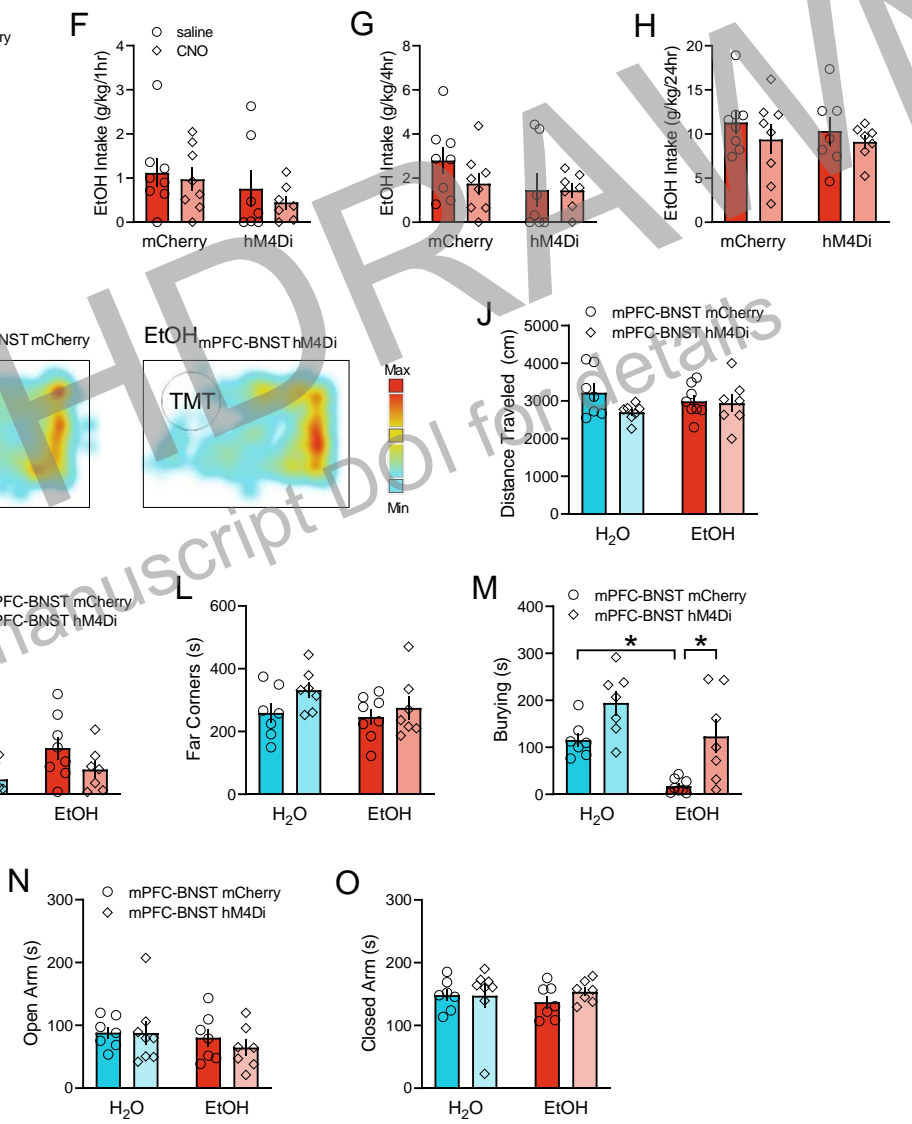

Figure 7. DREADD-mediated inhibition of mPFC-BNST pathway and assessment of EtOH drinking and TMT-related behaviors. A, Time course of mPFC-BNST chemogenetic strategy in C57BL/6J mice before EtOH and TMT. B, Images of AAV-hM4Di-mCherry expression in mPFC cell bodies, left, and BNST terminals, right $\left(\mathrm{H}_{2} \mathrm{O}\right.$ mCherry $\mathrm{n}=7, \mathrm{H}_{2} \mathrm{O}$ hM4Di-mCherry $\mathrm{n}=7$. EtOH mCherry $\mathrm{n}=8$, EtOH hM4DimCherry $n=7$ ). mCherry was enhanced with a GFP immunostain. Slice physiology validation of the DREADD strategy, in mPFC neurons, as represented by $\mathbf{C}$, hyperpolarization of resting membrane potential after CNO bath application. Inset scale bar indicates $2 \mathrm{mV}$ height and $30 \mathrm{sec}$ time. D, Latency to action potential threshold before and after CNO with $100 \mathrm{pA}$ current ramp steps. Scale bar indicates $20 \mathrm{pA}$ height and $100 \mathrm{~ms}$ time. E, EtOH drinking (g/kg/24hr) across 6 wks with mPFC-BNST hM4Di (red) or mCherry (light red). EtOH intake (g/kg) across F, $1 \mathrm{hr}, \mathbf{G}, 4 \mathrm{hr}$, and $\mathbf{H}, 24 \mathrm{hr}$ after i.p. saline (circles) or $3 \mathrm{mg} / \mathrm{kg}$ CNO (diamonds). I, Sample TMT heatmaps of EtOH mPFC-BNST mCherry (left) and EtOH mPFC-BNST hM4Di (right) mice. In the TMT test, J, distance traveled (cm), K, TMT contact, L, far corners (sec), and $\mathbf{M}$, burying (sec). In the elevated plus maze, duration in the $\mathbf{N}$, open arms (sec), and $\mathbf{O}$, closed arms (sec). $* \mathrm{p}<0.05$. 
bioRxiv preprint doi: https://doi.org/10.1101/773481; this version posted June 6, 2020. The copyright holder for this preprint (which was not certified by peer review) is the author/funder, who has granted bioRxiv a license to display the preprint in perpetuity. It is made available under aCC-BY-NC 4.0 International license.

\section{Figure 1 Suppl 1}
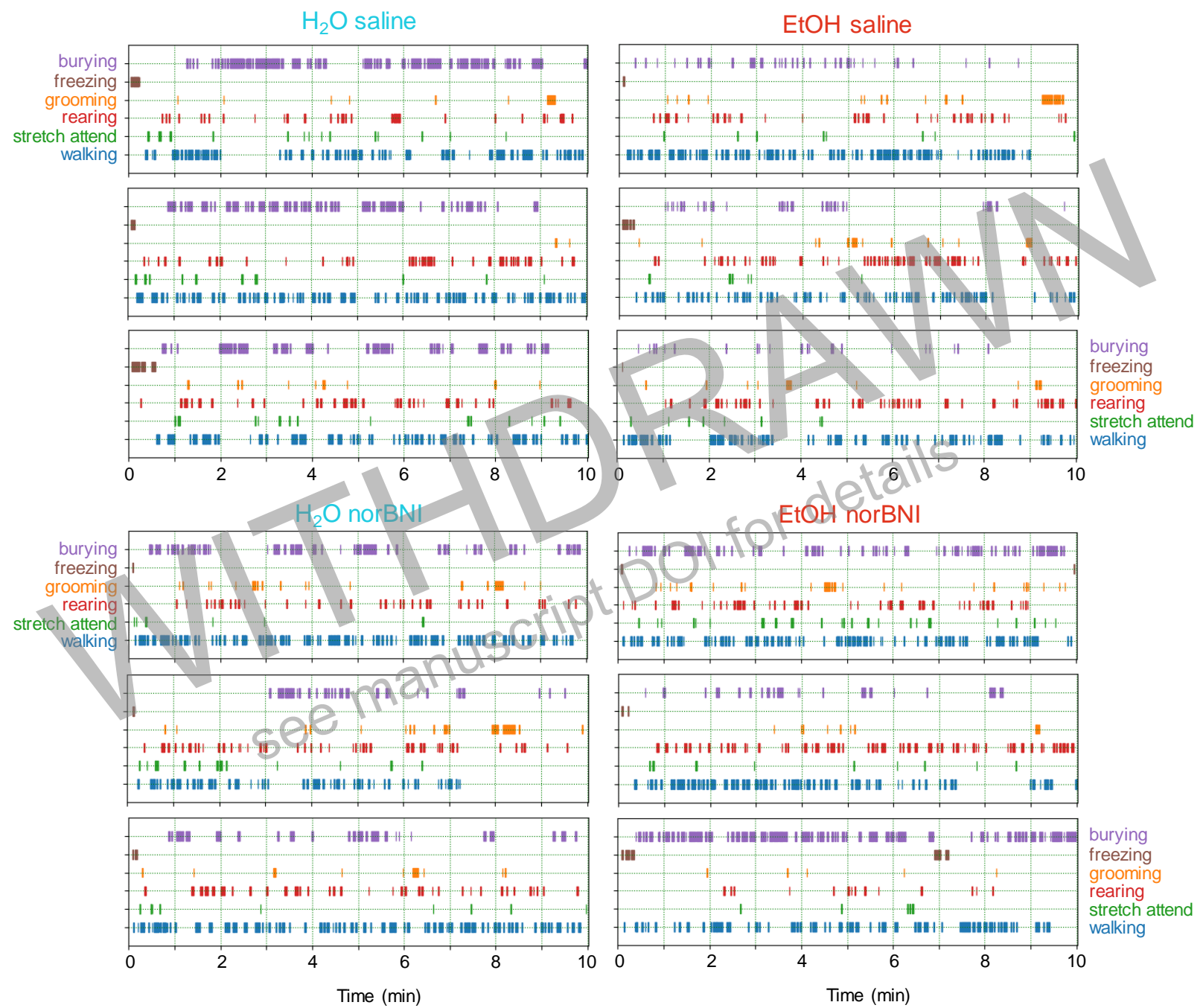

Figure 1 Suppl 1. Home cage TMT predator odor ethograms. Stress-related and exploratory behaviors were observed and plotted using BORIS behavioral software: burying (purple), freezing (brown), grooming (orange), rearing (red), stretch-attend (green), and walking (blue). $\mathrm{H}_{2} \mathrm{O}$ mice are in aqua on the left. EtOH mice are in red on the right. Saline-injected mice are the top plots over the $5 \mathrm{mg} / \mathrm{kg}$ norBNI-injected mice on the bottom. Ticks represent time and duration of behaviors during a 10 min test. 


\section{Figure 1 Suppl 2}

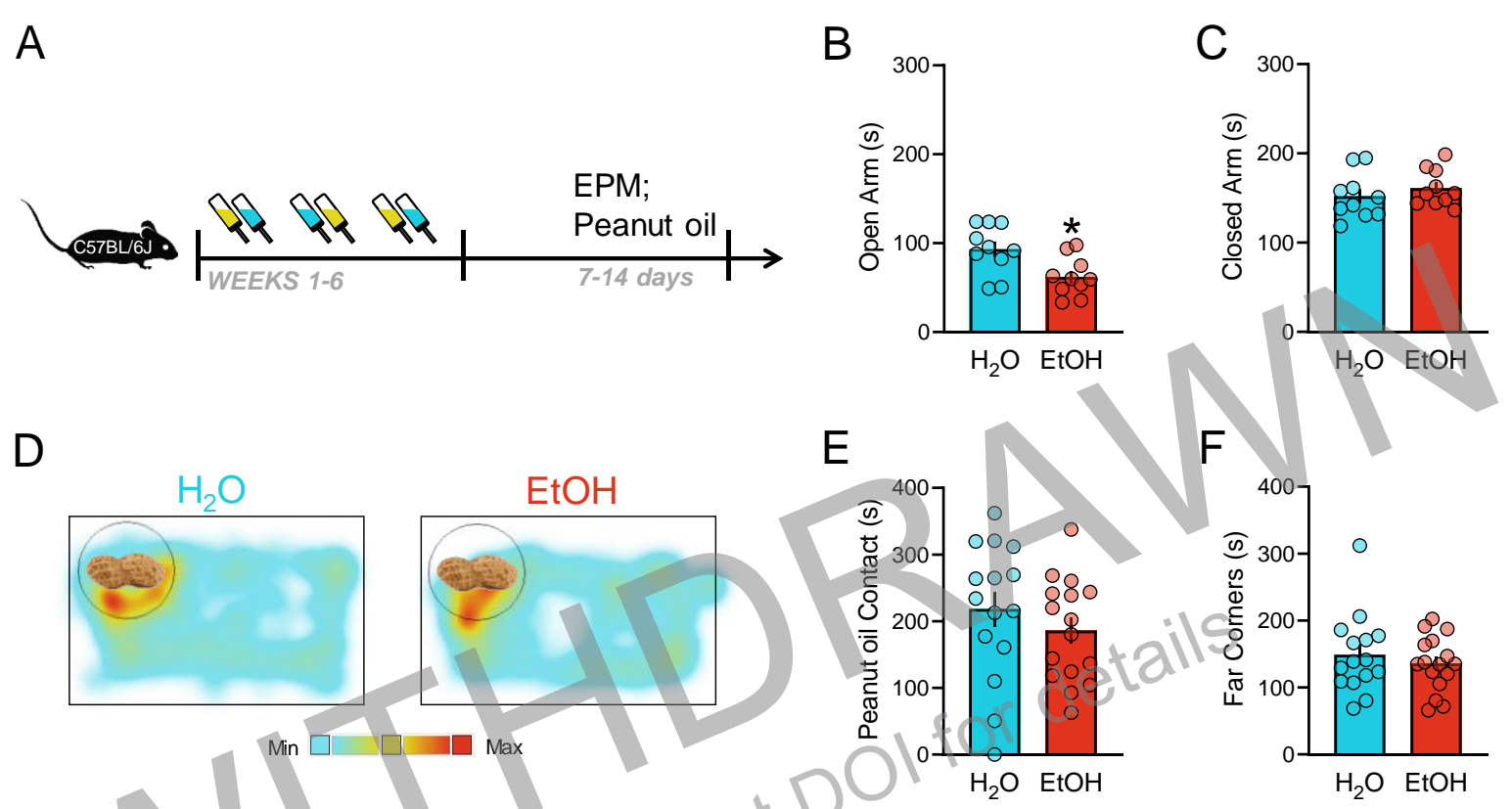

Figure 1 Suppl 2. Elevated plus maze and peanut oil tests after intermittent EtOH during protracted withdrawal. A, Schematic of elevated plus maze (EPM) and home cage peanut oil trial after 6 weeks of EtOH exposure, where time (s) spent in the $\mathbf{B}$, open arms and $\mathbf{C}$, closed arms was assessed. D, Representative heat maps of $\mathrm{H}_{2} \mathrm{O}$ and $\mathrm{EtOH}$ mice with peanut oil in the home cage. E, Contact with the peanut oil and $\mathbf{F}$, time in the far corners. ${ }^{*} \mathrm{p}<0.05$. 


\section{Fig 3 Suppl 1}

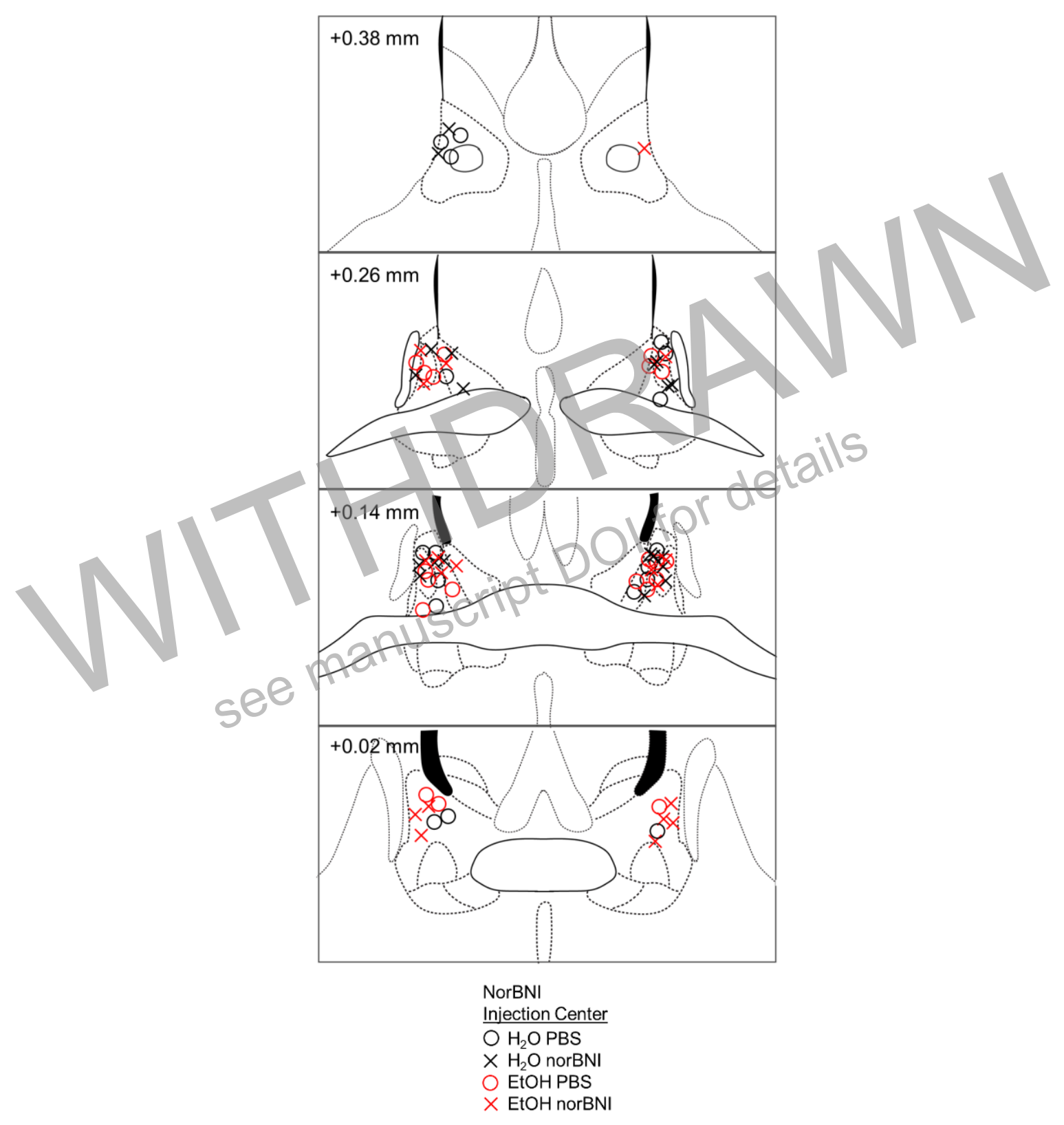

Figure 3 Suppl 1. Histological verification of stereotaxic injections in male mice. Correct placements of a single norBNI or PBS infusion are shown in coronal sections in millimeters from bregma surrounding the BNST of C57BL/6J mice. Circles represent the injection center of PBS, and crosses represent norBNI. Both groups had 10nl GFP to mark the injection site. 


\section{Figure 4 Suppl 1}

A

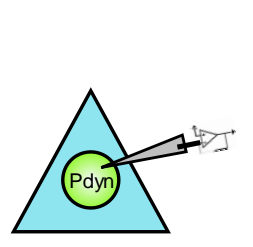

$\mathrm{B}$

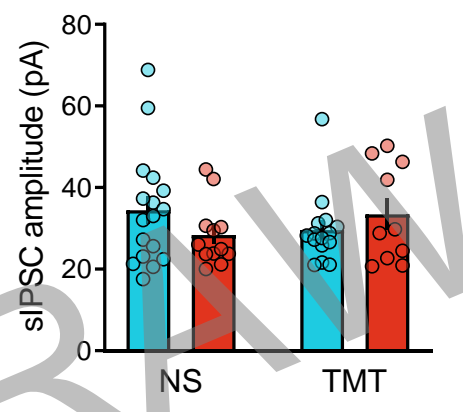

C

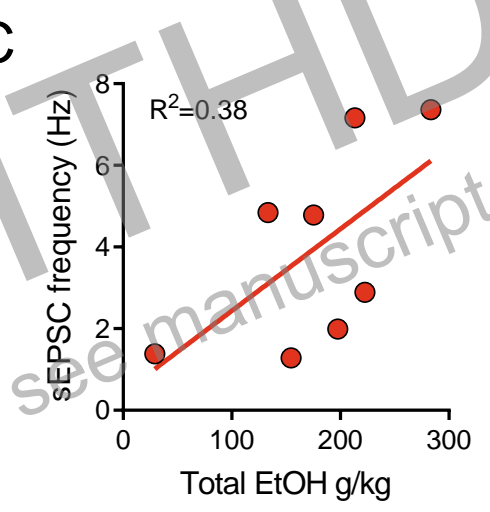

E
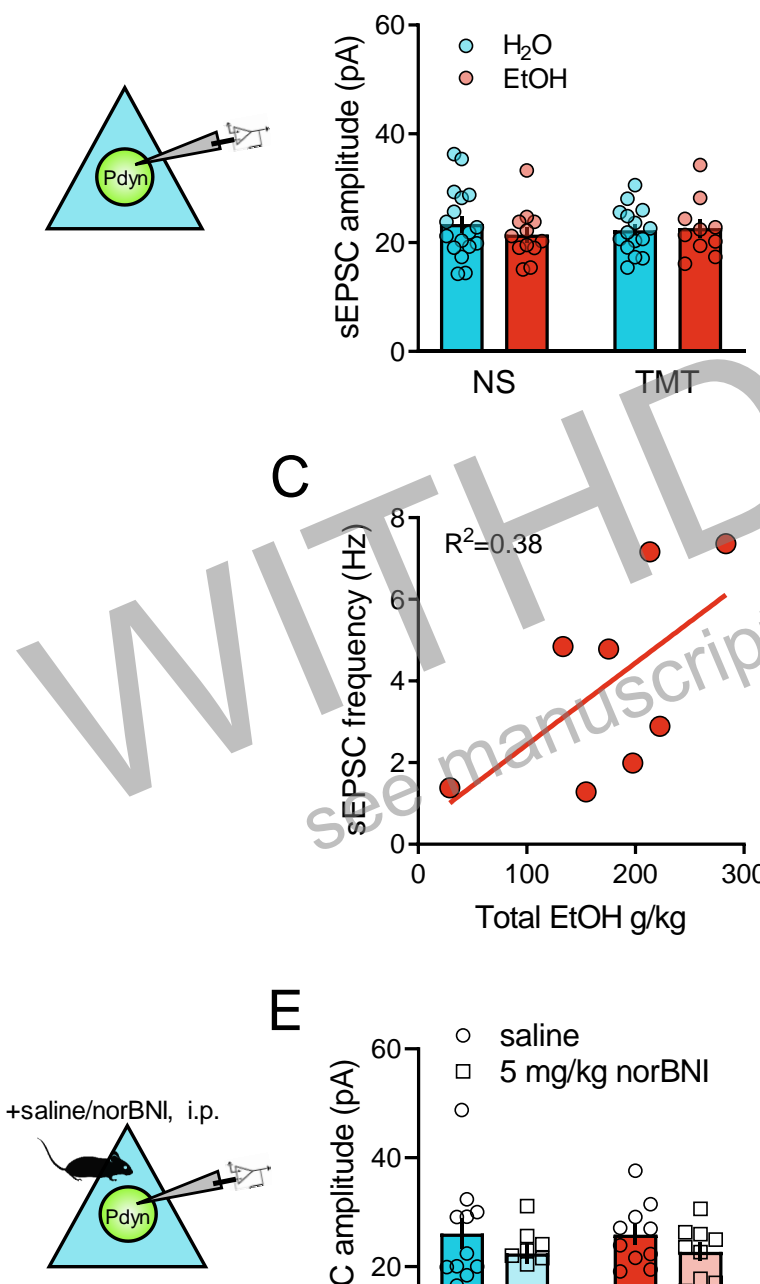

D

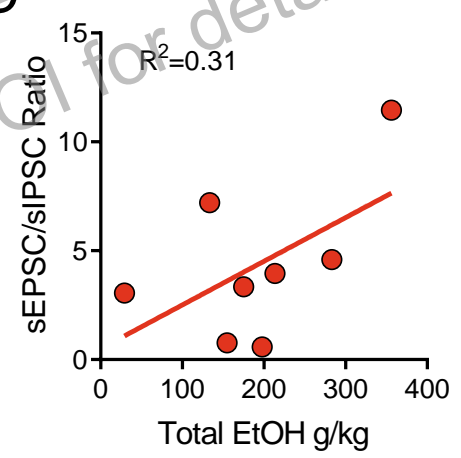

$\mathrm{F}$

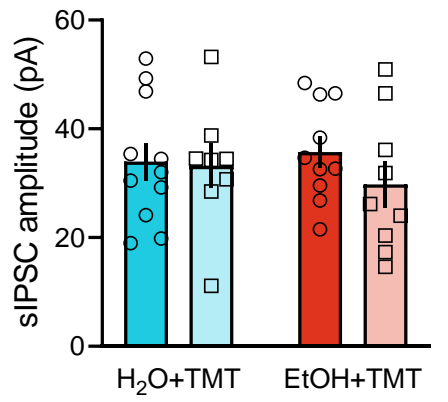

Figure 4 Suppl 1. A, TMT BNST ${ }^{\text {PDYN }}$ cell synaptic transmission sEPSC amplitude (pA). B, sIPSC amplitude (pA). Correlation between cumulative, total EtOH $(\mathrm{g} / \mathrm{kg}$ ) across six weeks and $\mathbf{C}$, sEPSC frequency $(\mathrm{Hz})$ and $\mathbf{D}$, sEPSC/sIPSC ratio in Pdyn-GFP mice after EtOH and TMT. E, NorBNI pretreatment BNST $^{\text {PDYN }}$ cell sEPSC amplitude (pA). F, sIPSC amplitude (pA). 
Figure 5 Suppl 1

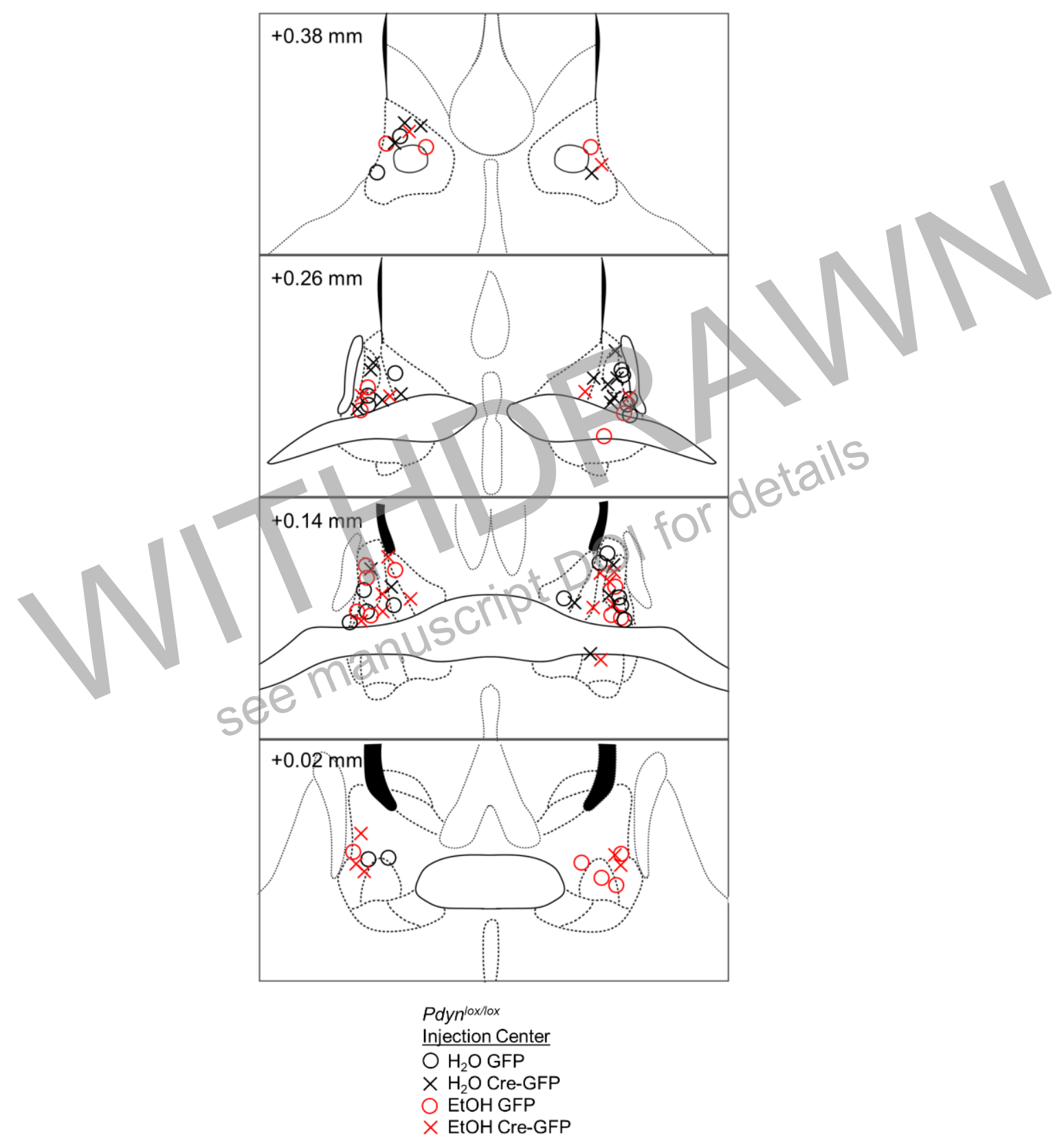

Figure 5 Suppl 1. Correct BNST placements of AAV-Cre-GFP or AAV-GFP infusion are shown in coronal sections in millimeters from bregma in a floxed Pdyn mouse line. Injection centers are represented by circles for GFP or crosses for Cre-GFP. 
Figure 6 Suppl 1
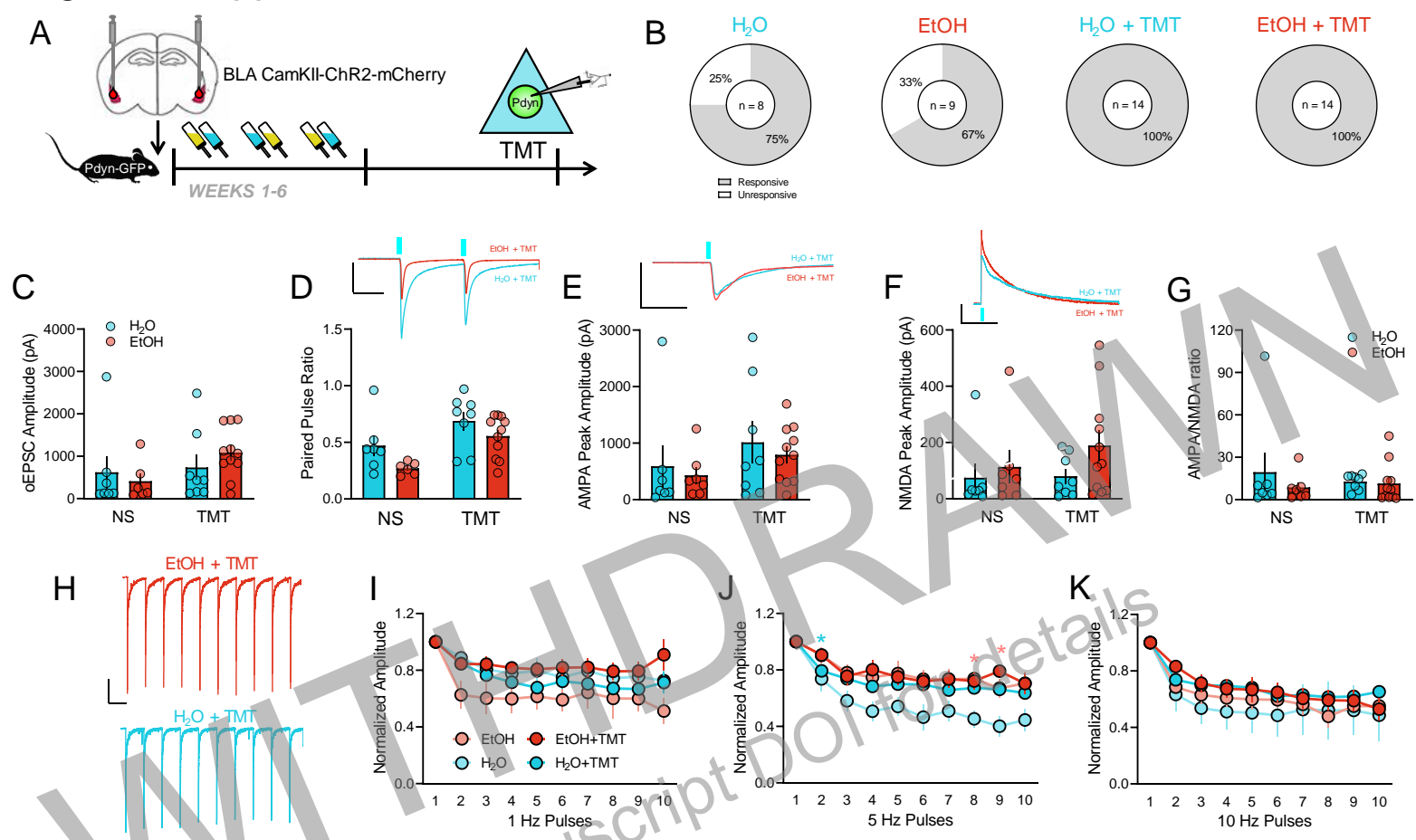

Figure 6 Suppl 1. Basolateral amygdala input onto BNST ${ }^{\mathrm{PDYN}}$ cells after history of alcohol and TMT exposure. A, Experimental design testing synaptic connectivity of basolateral amygdala (BLA) input to BNST $^{\text {PDYN }}$ cells using channelrhodopsin (ChR2) after EtOH and TMT. B, Proportions of light-responsive (white) and non-light-responsive (grey) $\mathrm{BNST}^{\mathrm{PDYN}}$ cells to optically-evoked EPSC in $\mathrm{H}_{2} \mathrm{O}(6 / 8$ responsive cells, $\mathrm{n}=3), \mathrm{EtOH}(6 / 9$ responsive cells, $\mathrm{n}=4), \mathrm{H}_{2} \mathrm{O}+\mathrm{TMT}$ (14/14 responsive cells, $\left.\mathrm{n}=4\right)$, and EtOH + TMT (14/14 responsive cells, $\mathrm{n}=4$ ) groups. C, BLA-BNST ${ }^{\text {PDYN }}$ oEPSC amplitude (pA). D, Paired pulse ratio. Inset example traces of $\mathrm{H}_{2} \mathrm{O}+$ TMT (aqua) and EtOH + TMT (red) with blue LED onset. Scale bar indicates $500 \mathrm{pA}$ height and $50 \mathrm{~ms}$ time. E, AMPA peak amplitude (pA). Inset AMPA traces of $\mathrm{H}_{2} \mathrm{O}+$ TMT (aqua) and EtOH + TMT (red) with blue LED onset. Scale bar indicates $1000 \mathrm{pA}$ height and $50 \mathrm{~ms}$ time. F, NMDA peak amplitude (pA). Inset NMDA traces of $\mathrm{H}_{2} \mathrm{O}+\mathrm{TMT}$ (aqua) and EtOH + TMT (red) with blue LED onset. Scale bar indicates $200 \mathrm{pA}$ height and $500 \mathrm{~ms}$ time. G, AMPA/NMDA ratio. H, Representative traces of $1 \mathrm{~Hz}$ pulse trains in EtOH + TMT (red) and $\mathrm{H}_{2} \mathrm{O}+$ TMT (aqua) BNST ${ }^{\text {PDYN }}$ cells. Scale bar indicates 200 pA height and $1 \mathrm{sec}$ time. oEPSC normalized amplitude across $\mathbf{I}, 1 \mathrm{~Hz}, \mathbf{J}, 5 \mathrm{~Hz}$, and $\mathbf{K}, 10 \mathrm{~Hz}$ pulse trains. $* \mathrm{p}<0.05$. 


\section{Figure 7 Suppl 1}

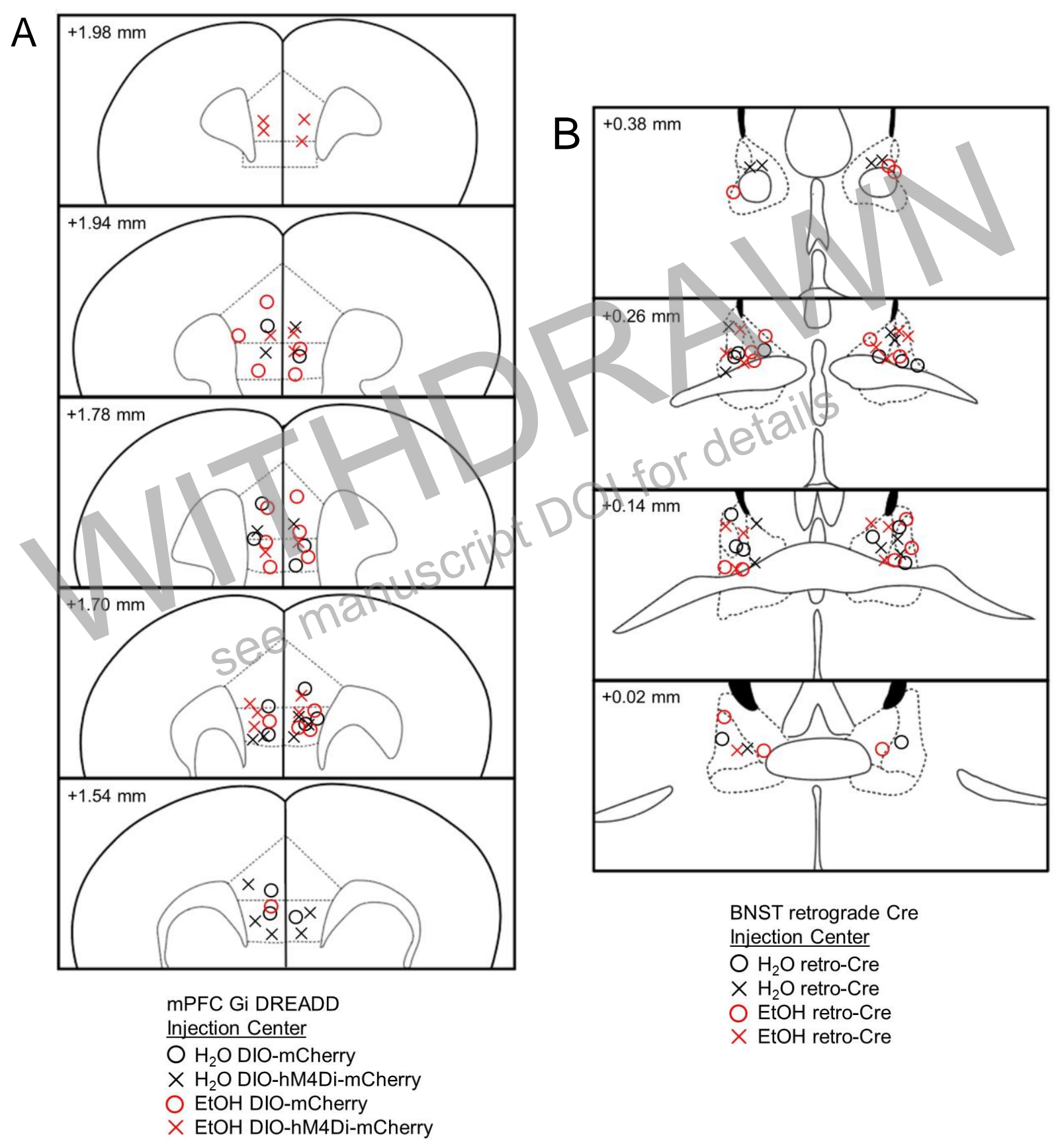

Figure 7 Suppl 1. A, mPFC placements of AAV-DIO-hM4Di-mCherry or AAV-DIO-mCherry and, B, BNST placements of retrograde AAV-Cre infusion are shown in coronal sections in millimeters from bregma in C57BL/6J mice. Injection centers are represented by circles for mCherry or crosses for hM4DimCherry. 